\title{
Flora do Espírito Santo: Campomanesia (Myrtaceae) ${ }^{\mathbf{1}}$
}

\author{
Flora of Espírito Santo: Campomanesia (Myrtaceae)
}

\author{
Jaquelini Luber ${ }^{2,5}$, Marla Ibrahim Uehbe De Oliveira ${ }^{3}$, Márcia Flores Da Silva Ferreira ${ }^{4}$ \\ \& Tatiana Tavares Carrijo ${ }^{2,4}$
}

\begin{abstract}
Resumo
Listagens florísticas realizadas para Angiospermas ou apenas para a família Myrtaceae no Espírito Santo apresentaram resultados divergentes com relação à riqueza de espécies de Campomanesia neste estado. $\mathrm{O}$ presente estudo visa elucidar esta questão a partir do desenvolvimento de uma abordagem florístico-taxonômica para o gênero no Espírito Santo. Foram analisadas coleções depositadas nos herbários CVRD, MBML, RB e VIES, e realizado trabalho de campo em localidades representativas de todas as fitofisionomias do Espírito Santo durante janeiro de 2015 a julho de 2016. Treze espécies de Campomanesia foram encontradas para o Espírito Santo. Dez dentre estas espécies tiveram sua ocorrência confirmada para o estado, duas são novas ocorrências, e uma é nova para a ciência (Campomanesia sepalifolia), sendo descrita e ilustrada nesse trabalho pela primeira vez. A caracterização morfológica das espécies foi realizada por meio de descrições e ilustrações; é apresentada uma chave dicotômica de identificação e mapas que representam a distribuição geográfica das espécies.
\end{abstract}

Palavras-chave: diversidade, espécie nova, flora, Floresta Atlântica, riqueza.

\begin{abstract}
Plant checklist made for Angiosperms or only for the family Myrtaceae in Espírito Santo presented divergent results regarding the richness of Campomanesia species in this state. The present study aims to elucidate this issue from the development of a floristic-taxonomic approach to the genus in the Espírito Santo state. Collections deposited at herbaria CVRD, MBML, RB and VIES were analyzed, and the fieldwork were made in localities representative of all the phytophysiognomies of Espírito Santo from january 2015 to july 2016. Ten of these species had their occurrence confirmed for the state, two are new records, and one is new to science (Campomanesia sepalifolia), being described and illustrated here for the first time. The morphological characterization of the species was made by descriptions and illustrations; an identification key and maps represented the species geographic distribution are provided.
\end{abstract}

Key words: diversity, new species, flora, Atlantic Forest, richness.

\section{Introdução}

O gênero neotropical Campomanesia Ruiz \& Pavón (McVaugh 1968; Landrum 1986) se distingue dos demais gêneros de Myrtaceae pelo ovário (3-)4-18 locular, e por apresentar uma falsa testa protetora resultante do desenvolvimento da parede do lóculo glandular (Landrum 1986).
Apesar de sua clara distinção em comparação aos demais gêneros de Myrtaceae, algumas espécies de Campomanesia são delimitadas por um conjunto de caracteres compartilhados, enquanto outras são circunscritas por caracteres morfológicos tênues, o que dificulta o entendimento dos limites morfológicos entre alguns táxons.

\footnotetext{
${ }^{1}$ Parte da dissertação de Mestrado do primeiro autor no curso de Pós-graduação em Biodiversidade Tropical, UFES.

${ }^{2}$ Universidade Federal do Espírito Santo, Centro Universitário Norte do Espírito Santo, Prog. Pós-graduação em Biodiversidade Tropical, Rod. BR-101 Norte, Km 60, Bairro Litorâneo, 29932-540, São Mateus, ES, Brasil.

${ }^{3}$ Universidade Federal de Sergipe, Centro de Ciências Biológicas e da Saúde, Depto. Biologia, Cidade Universitária Prof. José Olímpio de Campos, Av. Marechal Rondon s/n, Jardim Rosa Elze, 49100-000, São Cristóvão, SE, Brasil.

${ }^{4}$ Universidade Federal do Espírito Santo, Centro de Ciências Exatas, Naturais e da Saúde, Prog. Pós-graduação em Genética e Melhoramento, Alto Universitário s/n, Guararema, 29500-000, Alegre, ES, Brasil.

${ }^{5}$ Autor para correspondência: luber.bio@gmail.com
} 
O gênero foi descrito em 1794 (Ruiz \& Pávon 1794: 72) e, posteriormente, revisado por Landrum (1986). São reconhecidas 42 espécies, sendo todas registradas para o Brasil (BFG 2015). A maior parte dos táxons ocorre na Floresta Atlântica, na qual foram registradas 35 espécies (BFG 2015), sendo este o bioma de onde se tem mais informações sobre o gênero.

Há na literatura floras que trataram especificamente o gênero para o Rio de Janeiro (Carrara 1997), Paraná (Lima et al. 2011) e Bahia (Oliveira et al. 2012). Além destas contribuições, novas espécies do gênero foram descritas nos últimos anos para os estados de São Paulo (Kawasaki 2000), Espírito Santo (Landrum 2002), Goiás (Proença et al. 2010), Bahia (Landrum \& Oliveira 2010; Oliveira et al. 2013) e Pará (Proença et al. 2011). Algumas espécies foram tratadas, ainda, em floras locais ou listagens realizadas para a família Myrtaceae em localidades de Minas Gerais (Kawasaki 2004; Morais \& Lombardi 2006; Santos \& Sano 2012), Sergipe (Landim \& Landrum 2002), Rio Grande do Sul (Sobral 2003), Pernambuco (Amorim \& Alves 2012), Maranhão (Aragão \& Gonçalo 2008), Bahia (Stadnik et al. 2016) e Espírito Santo (Pereira \& Assis 2000; Assis et al. 2004; Giaretta et al. 2015).

As contribuições que incluíram ou trataram especificamente as espécies de Campomanesia no Espírito Santo foram realizadas em vegetação de Restinga (Pereira \& Assis 2000; Assis et al. 2004; Giaretta et al. 2015). Estes trabalhos ampliaram substancialmente o conhecimento sobre o gênero nesta fitofisionomia do estado, permanecendo as demais pouco conhecidas. Adicionalmente, três listagens quantificaram a riqueza de Campomanesia no Espírito Santo (Giaretta et al. 2015; BFG 2015; Dutra et al. 2015). As informações apresentadas nestas listagens quanto à riqueza do gênero no estado são contraditórias, variando entre 10 espécies (Giaretta et al. 2015), 11 espécies (BFG 2015) e 13 espécies (Dutra et al. 2015).

O objetivo deste trabalho foi investigar a riqueza de espécies de Campomanesia no Espírito Santo, ampliando o conhecimento sobre a taxonomia, morfologia e distribuição geográfica no estado. A caracterização morfológica das espécies foi apresentada por meio de descrições morfológicas e ilustrações. Também é apresentada uma chave de identificação dicotômica para as espécies, bem como mapas ilustrando a distribuição geográfica dos táxons estudados no Espírito Santo.

\section{Material e Métodos}

Este trabalho foi desenvolvido com base na análise de coleções depositadas em herbários e trabalho de campo. Exsicatas dos herbários com maior representatividade de coletas para o Espírito Santo foram visitados (CVRD, MBML, RB e VIES; siglas segundo Thiers, continuamente atualizado) e solicitados como empréstimo e/ou doação para o estudo morfológico. A identificação das espécies foi realizada com base em bibliografia especializada para Campomanesia (Landrum 1986; Lima et al. 2011; Oliveira et al. 2012). Adicionalmente, foram realizadas consultas on line de material digitalizado, incluindo materiais tipos (speciesLink, Reflora e Global Plants). Níveis infraespecíficos não foram considerados nesse estudo, devido à escassez de conhecimento sobre a real delimitação entre táxons.

O trabalho de campo consistiu em expedições a 24 localidades (Fig. 1) compreendendo todo o estado do Espírito Santo e suas diferentes fitofisionomias (Garbin et al. 2017), de janeiro de 2015 a julho de 2016. Em campo, foram observadas e registradas informações sobre os aspectos morfológicos das espécies in vivo, assim como características do ambiente, obtenção de registro fotográfico e registrada a coordenada geográfica por meio de GPS.

As descrições morfológicas foram realizadas com base nas medidas tomadas em material herborizado, sempre na parte mediana das estruturas analisadas. No caso das medidas realizadas nas lâminas foliares, foram mensuradas folhas a partir do terceiro nó. Os conceitos e terminologias empregados nas descrições seguem Hickey \& King (2000). As abreviaturas dos nomes dos autores das espécies estão de acordo com Brummitt \& Powell (1992) e a citação das obras e dos periódicos estão de acordo com Stafleu \& Cowan (1979) e Lawrence et al. (1968), respectivamente. A chave de identificação dicotômica buscou priorizar caracteres vegetativos e de fácil observação.

A distribuição geográfica das espécies no Espírito Santo foi representada por mapas confeccionados a partir de dados obtidos por georreferenciamento em campo, somado àqueles informados nas etiquetas das exsicatas analisadas. Para espécimes cujas coordenadas não estavam citadas nas etiquetas, estas foram obtidas utilizando o software Google Earth (2009). Apenas um material por município foi incluído nesta planilha, de maneira a evitar a sobreposição de pontos. Ao final, uma planilha foi elaborada contendo o nome 


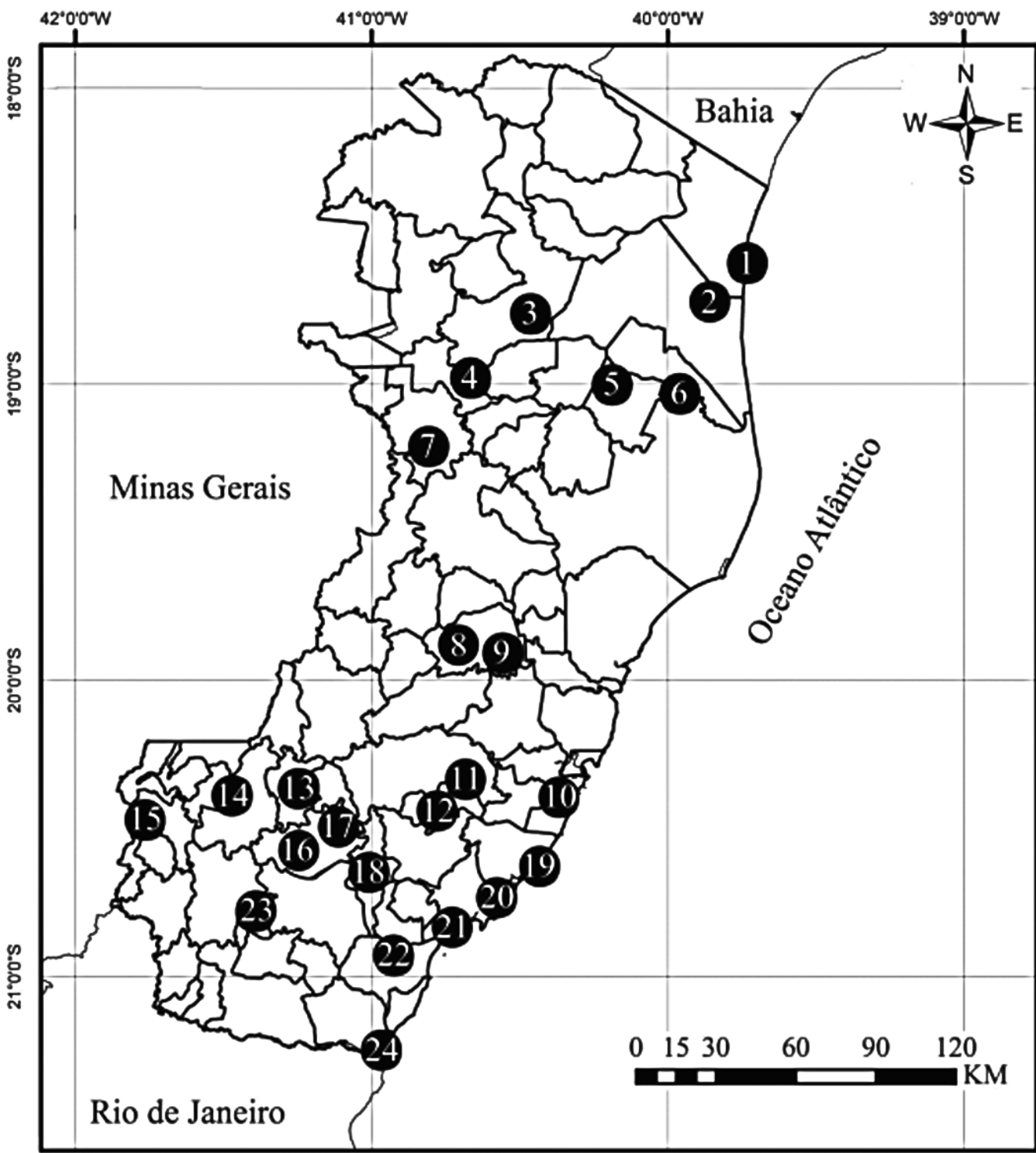

Figura 1 - Locais onde as coletas foram realizadas - 1. Parque Estadual de Itaúnas, Conceição da Barra; 2. Localidade em São Mateus; 3. Área de Proteção Ambiental Pedra do Elefante, Nova Venécia; 4. Localidade em Águia Branca; 5. Localidade em Vila Valério; 6. Reserva Biológica da Vale do Rio Doce, Linhares; 7. Monumento Natural dos Pontões Capixabas, Pancas; 8. Estação Biológica de Santa Lúcia, Santa Teresa; 9. Reserva Biológica Augusto Ruschi, Santa Teresa; 10. Localidade em Vila Velha; 11. Localidade em Domingos Martins; 12. Localidade em Marechal Floriano; 13. Localidade em Conceição do Castelo; 14. Localidade em Iúna; 15. Parque Nacional do Caparaó, Divino de São Lourenço; 16. Parque Estadual de Mata das Flores, Castelo; 17. Parque Estadual de Forno Grande, Castelo; 18. Localidade em Vargem Alta; 19. Parque Estadual Paulo Cézar Vinha, Guarapari; 20. Localidade em Anchieta; 21. Localidade em Piúma; 22. Localidade em Itapemirim; 23. Localidade em Jerônimo Monteiro; 24. Localidade em Presidente Kennedy. Figure 1 - Locations where collections were carried out - 1. Parque Estadual de Itaúnas, Conceição da Barra; 2. Location in São Mateus; 3. Área de Proteção Ambiental Pedra do Elefante, Nova Venécia; 4. Location in Águia Branca; 5. Location in Vila Valério; 6. Reserva Biológica da Vale do Rio Doce, Linhares; 7. Monumento Natural dos Pontões Capixabas, Pancas; 8. Estação Biológica de Santa Lúcia, Santa Teresa; 9. Reserva Biológica Augusto Ruschi, Santa Teresa; 10. Location in Vila Velha; 11. Location in Domingos Martins; 12. Location in Marechal Floriano; 13. Location in Conceição do Castelo; 14. Location in Iúna; 15. Parque Nacional do Caparaó, Divino de São Lourenço; 16. Parque Estadual de Mata das Flores, Castelo; 17. Parque Estadual de Forno Grande, Castelo; 18. Location in Vargem Alta; 19. Parque Estadual Paulo Cézar Vinha, Guarapari; 20. Location in Anchieta; 21. Location in Piúma; 22. Location in Itapemirim; 23. Location in Jerônimo Monteiro; 24. Location in Presidente Kennedy. 
das espécies, local de ocorrência e respectivas coordenadas. Estas informações serviram de base para a elaboração dos mapas utilizando o programa DIVA-GIS. O estado de conservação das espécies mencionado nos comentários teve como base o Livro Vermelho da Flora do Brasil (Martinelli \& Moraes 2013). O estado de conservação da nova espécie aqui descrita foi determinado seguindo os critérios propostos pela IUCN (2013), com o auxílio do GeoCat.

\section{Resultados e Discussão}

Treze espécies de Campomanesia foram registradas no Espírito Santo, representando aproximadamente $31 \%$ de todas as espécies conhecidas para o gênero, e aproximadamente $37 \%$ da riqueza estimada para a Floresta Atlântica.
Campomanesia sepalifolia Luber \& M. Ibrahim é aqui descrita como uma nova espécie para a ciência, e Campomanesia aromatica (Aubl.) Griseb. e C. phaea (O.Berg) Landrum se destacam como novas ocorrências para o Espírito Santo. Apenas Campomanesia espiritosantensis Landrum e C. sepalifolia são endêmicas do estado. Campomanesia dichotoma (O.Berg) Mattos e C. pubescens foram citadas por Dutra et al. (2015) e BFG (2015) para o Espírito Santo, enquanto $C$. lineatifolia foi citada por Giaretta et al. (2015), mas a ocorrência destas espécies no Espírito Santo não foi confirmada neste levantamento. As características morfológicas das espécies foram ilustradas (Figs. 2-9) e as localidades de ocorrência foram indicadas em mapas de distribuição geográfica (Fig. 10).

\section{Chave de identificação das espécies de Campomanesia no Espírito Santo}

1. Lâminas foliares obovadas ou ovadas, raro elípticas ou largo-elípticas; inflorescências unifloras ou em dicásios 3-floros; fruto ornamentado com protuberâncias cilíndricas ou com tricomas desenvolvidos semelhantes a tentáculos, quando liso com glândulas muito visíveis.

1'. Lâminas foliares elípticas ou lanceoladas, raro ovada ou obovadas; inflorescência unifloras, raro dicásios 3-floros; fruto liso sem glândulas visíveis

2. Nervura secundárias de 6-9 pares nas lâminas foliares; fruto ornamentado com tricomas desenvolvidos semelhantes a tentáculos salientes; ocorre frequentemente em afloramentos rochosos, raro em restingas 1. Campomanesia anemonea

2'. Nervuras secundárias de 4-7 pares nas lâminas foliares; frutos ornamentados com protuberâncias cilíndricas desenvolvidas (verrucosos) ou lisos, quando lisos com glândulas muito visíveis; ocorre em restingas e em matas de tabuleiro

8. Campomanesia macrobracteolata

3. Folhas opostas cruzadas; sépalas do botão floral com o ápice recurvado ou com divisões bem definidas, cuculadas (formando conchas) e uma bainha logo abaixo da inserção das sépalas

3'. Folhas opostas dísticas; sépalas do botão floral regulares, sem a morfologia citada acima ...

4. Sépalas do botão floral não cuculadas, com o ápice levemente recurvado para trás; flores geralmente sésseis, quando pediceladas de $0,5 \times 0,6 \mathrm{~cm}$; frutos globosos

11. Campomanesia sessiliflora

4'. Sépalas cuculadas (formando conchas) e uma bainha logo abaixo da inserção das sépalas; flores pediceladas de 2,4-9,1 × 1-2,5 mm; frutos discoides.

9. Campomanesia phaea

5. Cálice com abertura irregular na antese, apiculado

5'. Cálice com abertura regular na antese, não apiculado ....................................... 7

6. Árvore de $15-21 \mathrm{~m}$ de altura; lâmina foliar 10,46-20,37 × 5,12-9,51 cm, superfície plana; fruto rugoso ou não; encontrada em florestas

6. Campomanesia guazumifolia

6'. Árvore ou arbusto de 2-8 m de altura; lâmina foliar 4,76-12,59 × 2,79-5,25 $\mathrm{cm}$, superfície plana ou revoluta; fruto liso; encontrada em restinga ou em mata de tabuleiro.... 10. Campomanesia schlechtendaliana 
7. Domácias no encontro da nervura secundária com a primária presente...5. Campomanesia guaviroba

7'. Domácias no encontro da nervura secundária com a primária ausentes.............................................. 8

8. Anteras com ápice agudo, mais compridas do que largas; sépalas persistentes no fruto, maiores

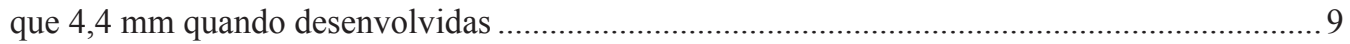

8'. Anteras com ápice arredondado, tanto compridas quanto largas; sépalas persistentes ou não no fruto, quando persistentes menores que $3,7 \mathrm{~mm}$ quando desenvolvidas ................................... 10

9. Sépalas cordiformes; bractéolas persistentes no fruto ........... 13. Campomanesia sepalifolia

9'. Sépalas deltoides; bractéolas ausentes no fruto ......................... 7. Campomanesia laurifolia

10. Nervuras secundárias inconspícuas ou impressas na face abaxial; inserção da antera dorsifixa; quando não, sépalas não persistentes no fruto .

10’. Nervuras secundária proeminentes na face abaxial; inserção da antera basifixa; sépalas persistentes no fruto .. 12

11. Nervuras secundárias impressas ou proeminentes na face abaxial; frutos com 2,2-6,4 $\mathrm{mm}$ de diâmetro; sépalas persistentes inteiras no fruto; ocorrência em afloramentos rochosos.

4. Campomanesia eugenioides

11'. Nervura secundárias inconspícuas na face abaxial; frutos com 9,1-14,8 mm de diâmetro; sépalas não persistentes inteiras no fruto; ocorrência conhecida para matas de tabuleiro..

3. Campomanesia espiritosantensis

12. Lâmina foliar bulada, cartáceas; disco floral convexo .

12. Campomanesia xanthocarpa

12'. Lâmina foliar lisa, coriácea ou membranáceas; disco floral plano a côncavo

2. Campomanesia aromatica

Descrição das espécies

1. Campomanesia anemonea Landrum, Brittonia 53(4): 536-538, $2002 . \quad$ Figs. 2a,b; 7a,b; 10a

Árvores ou arbustos de 4-12 m de alt. Folhas opostas dísticas com pecíolos 6,4-17,1 × 0,9-2,2 $\mathrm{mm}$, canaliculado ou cilíndrico, piloso, glanduloso ou não; lâminas 7,15-17,49 × 5,51-10,28 cm, cartáceas, elípticas, obovadas ou ovadas, ápice cuneado ou obtuso, base arredondada, cuneada ou obtusa, superfície lisa, plana, concolor ou discolor, lustrosa ou opaca na face abaxial e na face adaxial; domácias no encontro da nervura secundária com a primária ausentes; 6-9 pares de nervuras secundárias, impressas na face adaxial e proeminentes na abaxial, pilosas. Inflorescência (observadas em fruto) unifloras ou em dicásios 3 -floros. Flores não vistas; ovário (observado no fruto) 8-10 locular, ca. 8 óvulos por lóculo, 1-2 lóculos desenvolvidos. Frutos 12,2-25,1 × 16,9-29 $\mathrm{mm}$, epicarpo rígido quando maduro, globosos, pilosos, vermelhos quando maduros, ornamentados com tricomas desenvolvidos, semelhantes a tentáculos salientes, sépalas persistentes inteiras no fruto. Sementes ca. $8,7 \times 1,8-4,7 \mathrm{~mm}$, elípticas, ca. 8 por fruto.

Material examinado: Águia Branca, 16.III.2016, fr., J. Luber \& H.V. Pinto Júnior 222 (VIES); fr., J. Luber \& H.V. Pinto Júnior 223 (VIES). Conceição da Barra, 3.V.2016, fr., Q.S. Morais 119 (VIES). Linhares,
10.II.2005, fr., D.A. Folli 5031 (CVRD). Montanha, 28.XI.2012, fr., D.A. Folli 6957 (CVRD). Pinheiros, 10.V.2008, fr., D.A. Folli 6028 (CVRD); 10.XII.2009, fr., D.A. Folli 6511 (CVDR).

Campomanesia anemonea é endêmica do Brasil, tendo registro para o estado da Bahia e Espírito Santo (BFG 2015), permanecendo ainda sem avaliação quanto ao estado de conservação. Esta espécie havia sido previamente coletada apenas em formações florestais, mas no Espírito Santo foi encontrada em vegetação de afloramentos rochosos (Fig. 7a) e restingas, ambas as áreas situadas na região norte do estado (Fig. 10a). Coletada com fruto de novembro a maio.

Campomanesia anemonea assemelhase com C. macrobracteolata pela forma das folhas, pelas flores ocasionalmente em dicásio e pelos frutos ornamentados (Fig. 2a,b). Quando C. anemonea apresenta flores solitárias, estas são sésseis, e a ornamentação dos frutos são estruturas tentaculares (Figs. 2a; 7b), enquanto em C. macrobracteolata essas ornamentações são estruturas cilíndricas ou ausentes. Ambas as espécies ocorrem em formações florestais e vegetação de restinga, mas apenas $C$. anemonea ocorre em afloramentos rochosos (Fig. 7a).

Além de sua descrição original (Landrum 2002), C. anemonea foi descrita novamente no tratamento do gênero para a flora da Bahia (Oliveira 

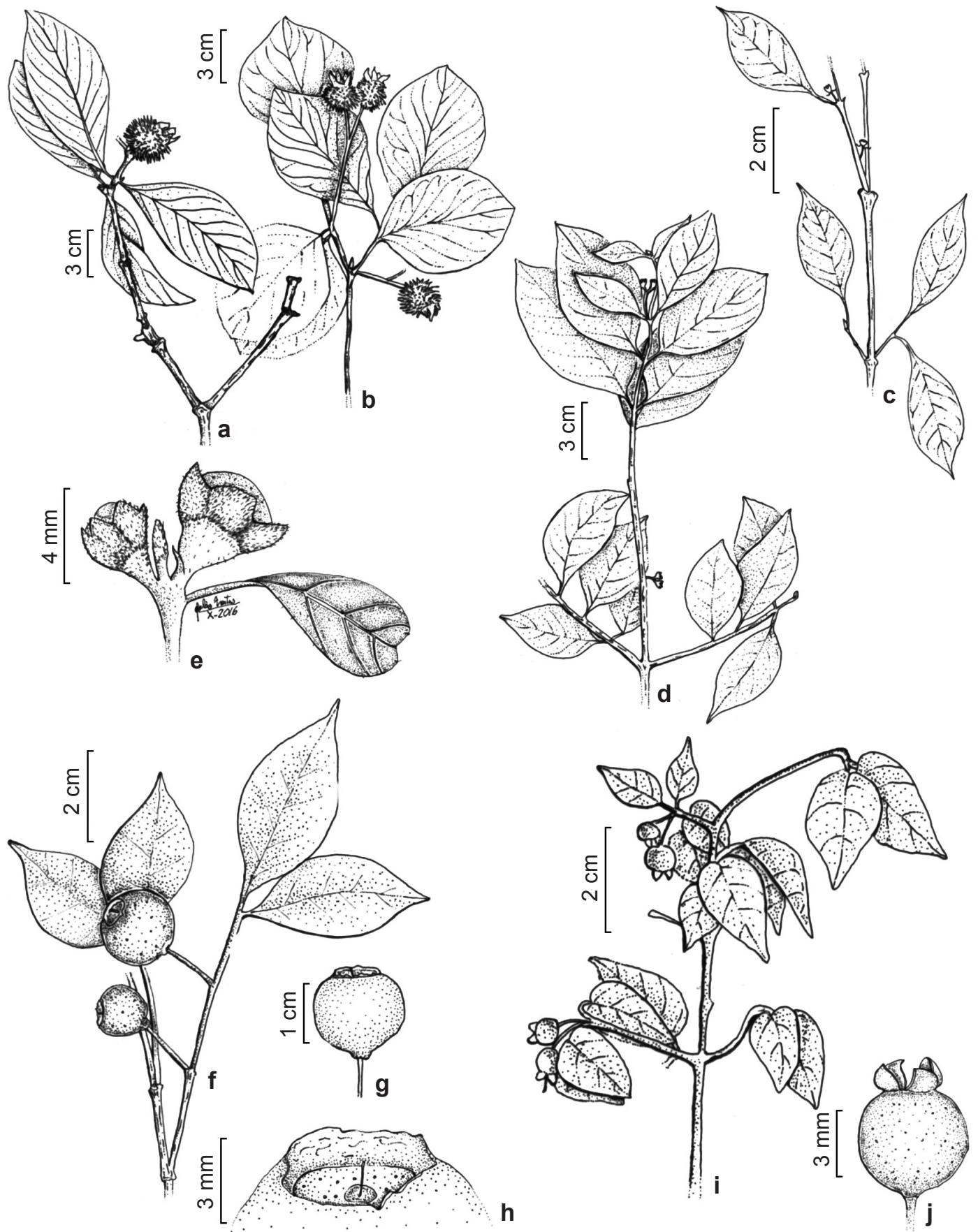

Figura 2 - a,b. Campomanesia anemonea - a. variação no formato das folhas; b. ornamentação do fruto. c-e. $C$. aromatica - c,d. variação no formato e no tamanho das folhas; e. detalhe do botão floral. f-h. C. espiritosantensis - f. formato das folhas; g. sépalas quebradiças no fruto maduro; h. disco floral plano a côncavo. i,j. C. eugenioides - i. formato das folhas; j. sépalas inteiras no fruto maduro. (a. J. Luber 223; b. Q.S. Moraes 119; c. D.A. Folli 6970; d,e. D.A. Folli 6958; f-h. D.A. Folli 5987; i,j. J. Luber 219).

Figure 2 - a,b. Campomanesia anemonea - a. leaf shape variation; b. fruit ornamentation. c-e. C. aromatica - c,d. leaf shape and size variation; e. flower bud in detail. f-h. C. espiritosantensis - f. leaf shape; g. sepals brittle in mature fruit; h. floral disc not prominent. i,j. C. eugenioides - i. leaf shape; j. sepals entire in mature fruit. (a. J. Luber 223; b. Q.S. Moraes 119; c. D.A. Folli 6970; d,e. D.A. Folli 6958 ; f-h. D.A. Folli 5987; i,j. J. Luber 219). 
et al. 2012), mas o fruto não foi observado em ambas as obras, sendo descrito e ilustrado aqui pela primeira vez.

2. Campomanesia aromatica (Aubl.) Griseb., Flora of the British West Indian Islands 242. 1864.

Figs. 2c-e; 10a

Árvores ou arbustos de 2-9 m de alt. Folhas opostas dísticas com pecíolos 5,4-11,4 × 0,5-1,8 mm, canaliculado, piloso, glanduloso; lâminas 3,91-10,79 × 1,18-5,96 cm, coriáceas ou membranáceas, lanceoladas ou ovadas, ápice agudo ou atenuado, base arredondada, atenuada ou cuneada, superfície lisa, plana, concolor ou discolor, lustrosa ou opaca na face abaxial e na face adaxial; domácias no encontro da nervura secundária com a primária presentes; 5-8 pares de nervuras secundárias, proeminentes na face abaxial e impressas na face adaxial, pilosas. Inflorescência unifloras. Flores com pedicelo 3,9-37,6 × 0,3-0,8 $\mathrm{mm}$, piloso, raro glanduloso; brácteas $5-7,4$ $\times 1,1-2 \mathrm{~mm}$, sésseis, lanceoladas ou lineares, membranáceas; bractéolas $1,1-1,3 \times 0,2-0,5$ $\mathrm{mm}$, sésseis, estreito-triangulares ou lineares, membranáceas, não persistentes no fruto; botão $3,2-6 \times 3,1-9 \mathrm{~mm}$, cálice com abertura regular na antese, não apiculado; (4-)5-sépalas, 1,6-3,7 $\times 1,8-3 \mathrm{~mm}$, regulares, coriáceas, deltoides, face interna pilosa, glandular ou não, face externa pilosa, glandular; pétalas não observadas; estames ca. 150; filete 1-1,2 mm compr., inserção basifixa, glândula terminal presente ou não; antera com ápice arredondado 0,2-0,9 × 0,1-0,2 mm; estilete 1,1-3,3 mm compr.; disco floral côncavo a plano ca. $3,8 \mathrm{~mm}$ diâm., piloso, não glanduloso; ovário 4-9 locular, 10-18 óvulos por lóculo, lóculos desenvolvidos não observados. Frutos não mensurados, epicarpo rígido quando maduro, globosos, pilosos e lisos, sépalas persistentes inteiras no fruto. Sementes não vistas.

Material examinado: Anchieta, 10.X.2009, fr., J.M.L. Gomes 3749 (VIES). Montanha, 29.XI.2012, bot., D.A. Folli 6958 (CVRD); 17.VI.2012, bot. e fl., D.A. Folli 6870 (CVRD). Santa Teresa, 30.XI.1999, fl., V. Demuner e W. Pizziolo 266 (MBML).

Campomanesia aromatica tem registro para o Brasil, Bolívia, Guiana, Guiana Francesa, Suriname, Trindade e Tobago e Venezuela (Landrum 1986; Trópicos 2016). No Brasil, era registrada para os estados do Pará, Bahia, Sergipe, Ceará e Paraíba (BFG 2015), sendo uma nova ocorrência para o estado do Espírito Santo. Campomanesia aromatica é categorizada como pouco preocupante (LC) quanto ao risco de extinção (BFG 2015). Apesar de possuir apenas quatro coleções para o estado, C. aromatica encontra-se amplamente distribuída (Fig. 10a), ocorre em vegetação de restinga assim como nas regiões montanhosas. Coletada com botão e flor nos meses de junho e novembro, e com fruto jovem em outubro.

Campomanesia aromatica assemelha-se com C. xanthocarpa pelo formato lanceolado das lâminas foliares e pelo diâmetro do disco floral $(3,8$ a $3,9 \mathrm{~mm})$. No entanto, C. aromatica apresenta disco floral plano a côncavo, como o de $C$. espiritosantensis (Fig. 2h), enquanto este é convexo em C. xanthocarpa. Além disso, a superfície das lâminas foliares são lisas, enquanto que em $C$. xanthocarpa a superfície das lâminas foliares são buladas, raramente lisas. Campomanesia aromatica apresentou grande variação nas dimensões e consistência (coriácea ou membranácea) das lâminas foliares (Fig. 2c,d).

3. Campomanesia espiritosantensis Landrum, Brittonia 39(2): 245-247, f. 1. 1987.

Figs. 2f-h; 10a

Árvores de 8-10 m de alt. Folhas opostas dísticas com pecíolos 4,3-6,3 × 0,4-0,8 mm, canaliculado, piloso, glanduloso; lâminas 4,467,14 × 2,06-2,91 cm, cartáceas, elípticas, ápice acuminado, base cuneada, superfície lisa, plana, discolor, lustrosa na face abaxial e na face adaxial; domácias no encontro da nervura secundária com a primária ausentes; $5-7$ pares de nervuras secundárias, inconspícuas na face abaxial e impressas na face adaxial, glabras. Inflorescência unifloras. Flores com pedicelo $8,1-17,4 \times 0,5-0,9$ $\mathrm{mm}$, piloso, glanduloso; brácteas e bractéolas não observadas; cálice e corola não observadas; disco floral côncavo a plano ca. 8,1 mm diâm., glabro, glanduloso; ovário ca. 7 locular, óvulos por lóculo não observado, ca. 1 lóculo desenvolvido. Frutos 9,1-14,8 × 10,1-15,9 mm, epicarpo rígido quando maduro, globosos, glabros, amarelos quando maduros, lisos, sépalas não persistentes inteiras no fruto. Sementes ca. 5,4 × 2,6 mm, elípticas, ca. 1 por fruto.

Material examinado: Linhares, 2.II.2004, fr., D.A. Folli 4750 (CVRD); 24.III.2008, fr., D.A. Folli 5987 (CVRD).

Campomanesia espiritosantensis é endêmica do Espírito Santo (BFG 2015), sendo sua ocorrência conhecida apenas para o município de Linhares (Fig. 10a). Esta espécie foi categorizada como criticamente em perigo (CR) (BFG 2015). Coletada com fruto em fevereiro e março. 

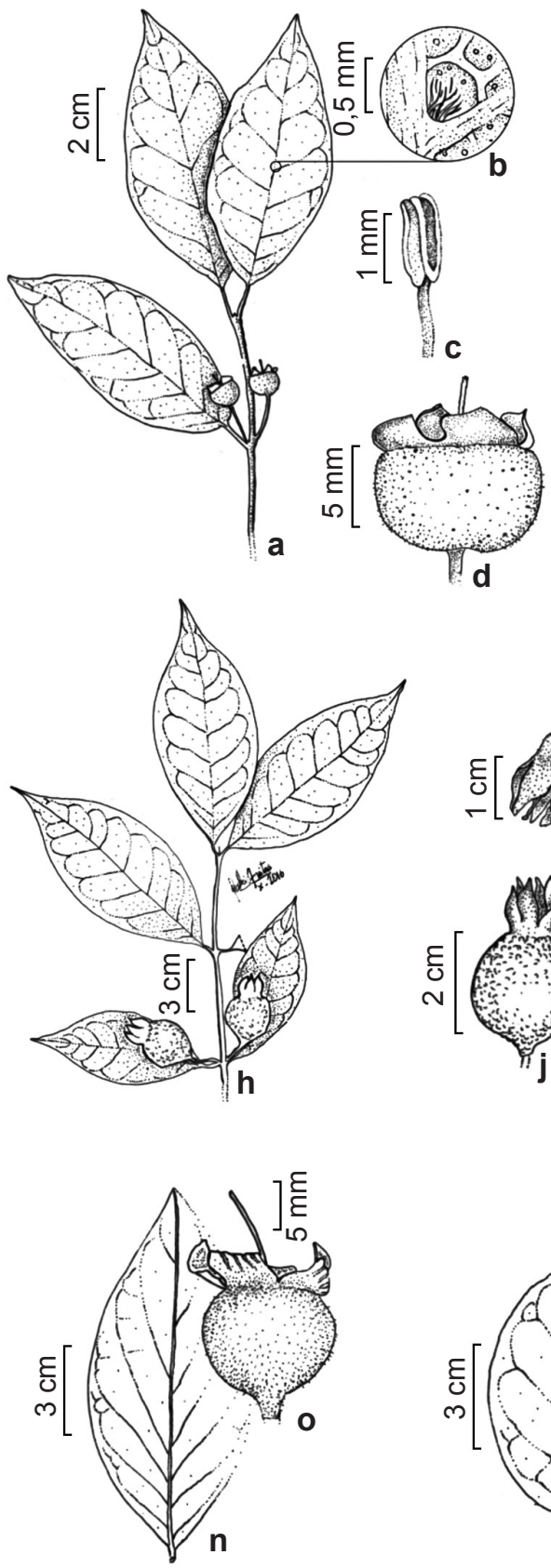
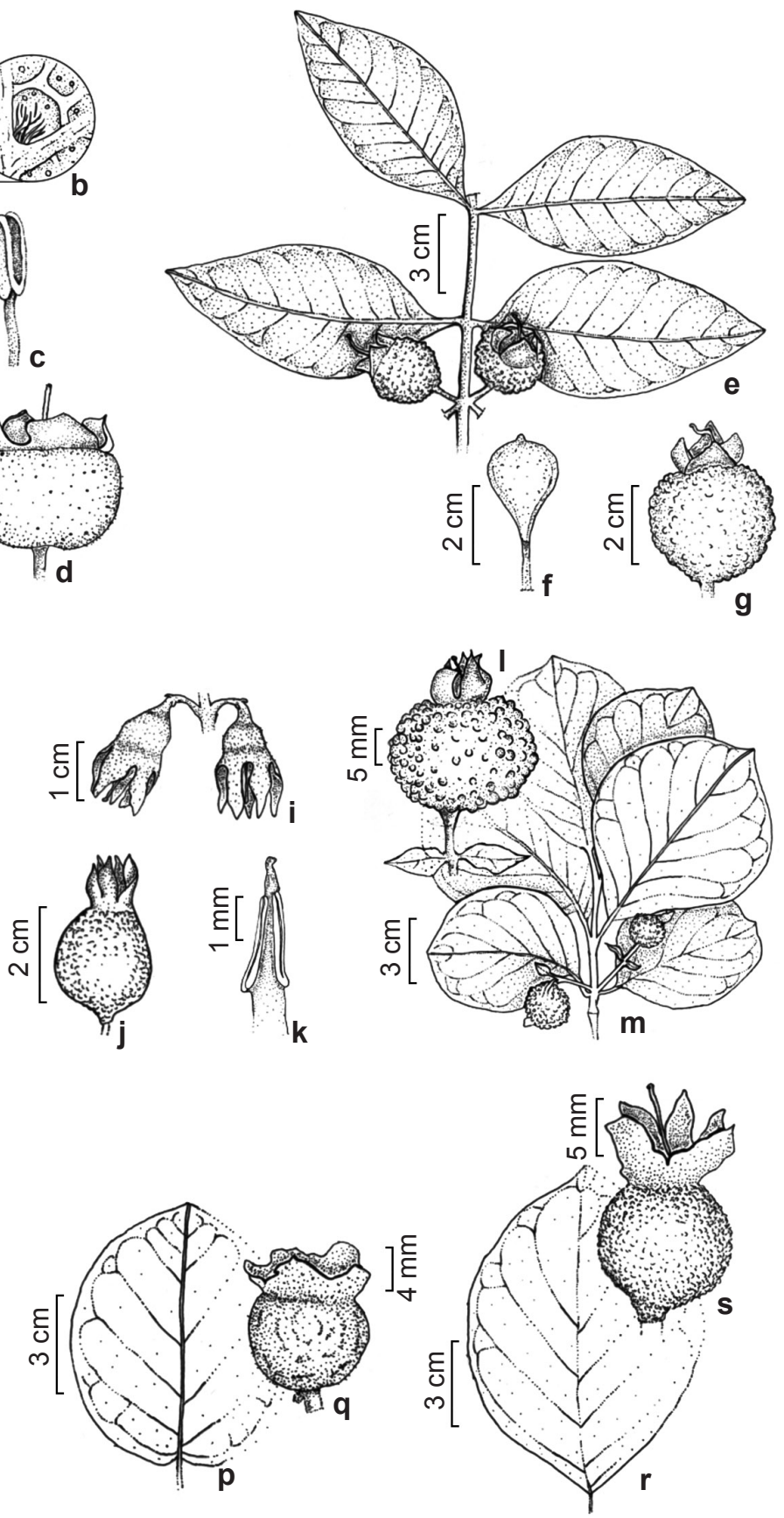

Figura 3 - a-d. Campomanesia guaviroba - a. formato das folhas; b. domácias nas nervuras secundárias; c. formato das anteras; d. formato do fruto. e-g. C. guazumifolia - e. formato da folha; f. botão floral apiculado; g. fruto rugoso. h-k. C. laurifolia - h. formato da folha; i. botão floral; j. formato do fruto; k. formato da antera. 1-s. C. macrobracteolata - 1 . ornamentação do fruto; m. forma da folha; n,p,r. variação no formato das folhas; o,q,s. variação na ornamentação dos frutos. (a-d. L. Kollmann 1119; e-g. J. Zorzanelli 1360; h,j,k. G.S. Siqueira 466; i. J. Luber 233; 1,m. J. Luber 236; n,o. A.M. Assis 1295; p,q. J.Luber 232; r,s. J. Luber 212).

Figure 3 - a-d. Campomanesia guaviroba - a. leaf shape; b. domatium in the secondary veins; c. anther shape; d. shape fruit. e-g. $C$. guazumifolia - e. leaf shape variation; f. flower bud apiculate; g. fruit rugose. h-k. C. laurifolia $-\mathrm{h}$. leaf shape variation; i. floral bud and antopodium in detail; j. fruit; k. anther shape. 1-s. C. macrobracteolata - 1. fruit ornamentation variation; m. leaf shape variation; n,p,r. leaf shape variation; o,q,s. fruit ornamentation variation. (a-d. L. Kollmann 11 19; e-g. J. Zorzanelli 1360; h,j,k. G.S. Siqueira 466; i. J. Luber 233; 1,m. J. Luber 236; n,o. A.M. Assis 1295; p,q. J.Luber 232; r,s. J. Luber 212). 
Campomanesia espiritosantensis assemelhase a $C$. eugenioides pelo tamanho das lâminas foliares (variando de 1,88-7,14 ×0,49-2,91 mm) e pelo formato elíptico destas. Morfologicamente, C. espiritosantensis se caracteriza pelo porte arbóreo (não arbustivo), pelas nervuras secundárias inconspícuas (Fig. 2f), pelas sépalas não se manterem inteiras no fruto desenvolvido (Fig. $2 \mathrm{~g}, \mathrm{~h})$, pelo disco floral não ser convexo e pelos frutos maiores $(9,1-14,8 \times 10,1-15,9 \mathrm{~mm}$, e não de $2,2-6,4 \times 2,1-7,1 \mathrm{~mm})$. Em material herborizado, C. espiritosantensis apresenta folhas e pecíolos igualmente marrons, enquanto as folhas de $C$. eugenioides geralmente apresentam coloração amarelada e o pecíolo escuro. Somado às diferenças morfológicas, C. espiritosantensis foi encontrada apenas em formações florestais, enquanto $C$. eugenioides foi encontrada estritamente em afloramentos rochosos (Fig. 7c,d).

\section{Campomanesia eugenioides (Cambess.)} D.Legrand ex Landrum, Flora Neotropica 45: 28. 1986.

Figs. 2i,j; 7c,d; 10a

Árvores ou arbustos de 2-5 m de alt. Folhas opostas dísticas com pecíolos 2,9-6,2 × 0,3-1 $\mathrm{mm}$, canaliculado, glabro ou piloso, glanduloso; lâminas $1,88-5,2 \times 0,49-2,42 \mathrm{~cm}$, cartáceas, ovadas ou elípticas, ápice agudo ou atenuado, base arredondada ou cuneada, superfície lisa, plana, às vezes revoluta, concolor, lustrosa ou opaca na face abaxial e na face adaxial; domácias no encontro da nervura secundária com a primária ausentes; 4-8 pares de nervuras secundárias, impressas ou proeminentes na face abaxial e impressas na face adaxial, glabras. Inflorescência unifloras. Flores com pedicelo 5,7-19,4 × 0,2-3 mm, glabro, glanduloso; brácteas $1,8-5 \times 0,8-2,5 \mathrm{~mm}$, sésseis, lanceoladas ou oblongas, cartáceas; bractéolas 2,3$3 \times 0,2-2 \mathrm{~mm}$, sésseis, lineares ou oblanceoladas, cartáceas, não persistentes no fruto; botão $2-6,5$ $\times 1,5-5,1 \mathrm{~mm}$, cálice com abertura regular na antese, não apiculado; (4-)5-sépalas, 2,1-3 × 2-3,2 mm, regulares, cartáceas, deltoides, face interna glabra ou pilosa, não glandular, face externa glabra, glandular; 4-pétalas, ca. 6,8 ×3,4-5,2 mm, glabra, glandular; estames ca. 120; filete ca. 3,1 mm compr., inserção dorsifixa, glândula terminal presente ou não; antera com ápice arredondado ca. $3 \times 1 \mathrm{~mm}$; estilete 3,5-5,6 mm compr.; disco floral convexo 3-3,9 mm diâm., glabro, não glanduloso; ovário 4-6 locular, 4-10 óvulos por lóculo, 1-3 lóculos desenvolvidos. Frutos 2,2-6,4 × 2,1-7,1 $\mathrm{mm}$, epicarpo rígido quando maduro, globosos, glabros, vermelhos quando maduros, lisos, sépalas persistentes inteiras no fruto. Sementes $3,1 \times 1,5$ $\mathrm{mm}$, elípticas, ca. 3 por fruto.

Material examinado: Águia Branca, 26.IV.2006, fr., V. Demuner 2225 (MBML); 19.X.2006, bot. e fl., V. Demuner 3008 (MBML); 3.X.2007, bot., H.Q. Boudet Fernandes 3424 (MBML); 3.X.2007, fl., H.Q. Boudet Fernandes et al. 3421 (MBML); 20.XII.2007, bot. e f1., V. Demuner 4833 (MBML); 19.XI.2009, fr., E.S. Leal 65 (MBML). Nova Venécia, 12.I.2008, fl., M.C. Souza et al. 580 (VIES); 14.I.2009, fr., A.P. Fontana 5772 (MBML); 5.V.2015, fr., J. Luber et al. 83 (VIES); 23.VI.2015, bot., J. Luber et al. 124 (VIES); 23.VI.2015, bot., J. Luber et al. 125 (VIES); 18.IX.2015, fr., J. Luber et al. 195 (VIES).

Campomanesia eugenioides é endêmica do Brasil, tendo registro para toda região litorânea, do estado da Paraíba até o estado de Santa Catarina, e também para os estados de Minas Gerais, Goiás, Mato Grosso, Distrito Federal e Tocantins (BFG 2015), sendo categorizada como pouco preocupante (LC) quanto ao estado de conservação (BFG 2015). No Espírito Santo, a espécie foi encontrada em formações de afloramentos rochosos da região norte do estado (Fig. 10a). Os indivíduos apresentam distribuição agregada, sempre em áreas abertas. Coletada com flores de outubro a janeiro, e com frutos de setembro a maio.

Campomanesia eugenioides assemelha-se com C. espiritosantensis pelo tamanho das lâminas foliares (variando de 1,88-7,14 × 0,49-2,91 $\mathrm{mm}$ ) e pelo formato elíptico destas. No entanto, C. eugenioides difere pelo porte arbustivo (não arbóreo), pelas nervuras secundárias impressas (Fig. 2i) (não inconspícuas), pelas sépalas se manterem inteiras no fruto desenvolvido (Figs. $2 \mathrm{j}$; 7d), pelo disco floral ser convexo como o de C. xanthocarpa (Fig. 6e) e pelos frutos menores $(2,2-6,4 \times 2,1-7,1 \mathrm{~mm}$, e não de $9,1-14,8 \times 10,1-$ $15,9 \mathrm{~mm}$ ). As folhas de C. eugenioides em material herborizado são geralmente amareladas, sendo o pecíolo escuro, diferente de C. espiritosantensis, cujas folhas e pecíolos são igualmente marrons.

5. Campomanesia guaviroba (DC.) Kiaersk., Enumeratio Myrtacearum Brasiliensium: 8. 1893.

Figs. 3a-d; 10b

Árvores ou arbustos de 1,5-13 m de alt. Folhas opostas dísticas com pecíolos 4,4-18,1 $\times 0,4-1,5 \mathrm{~mm}$, canaliculado, glabro ou piloso, glanduloso ou não; lâminas 3,89-11,79 × 1,27-6,14 $\mathrm{cm}$, cartáceas, elípticas, obovadas ou ovadas, ápice atenuado, base arredondada ou cuneada, superfície lisa, plana, às vezes revoluta, discolor, 

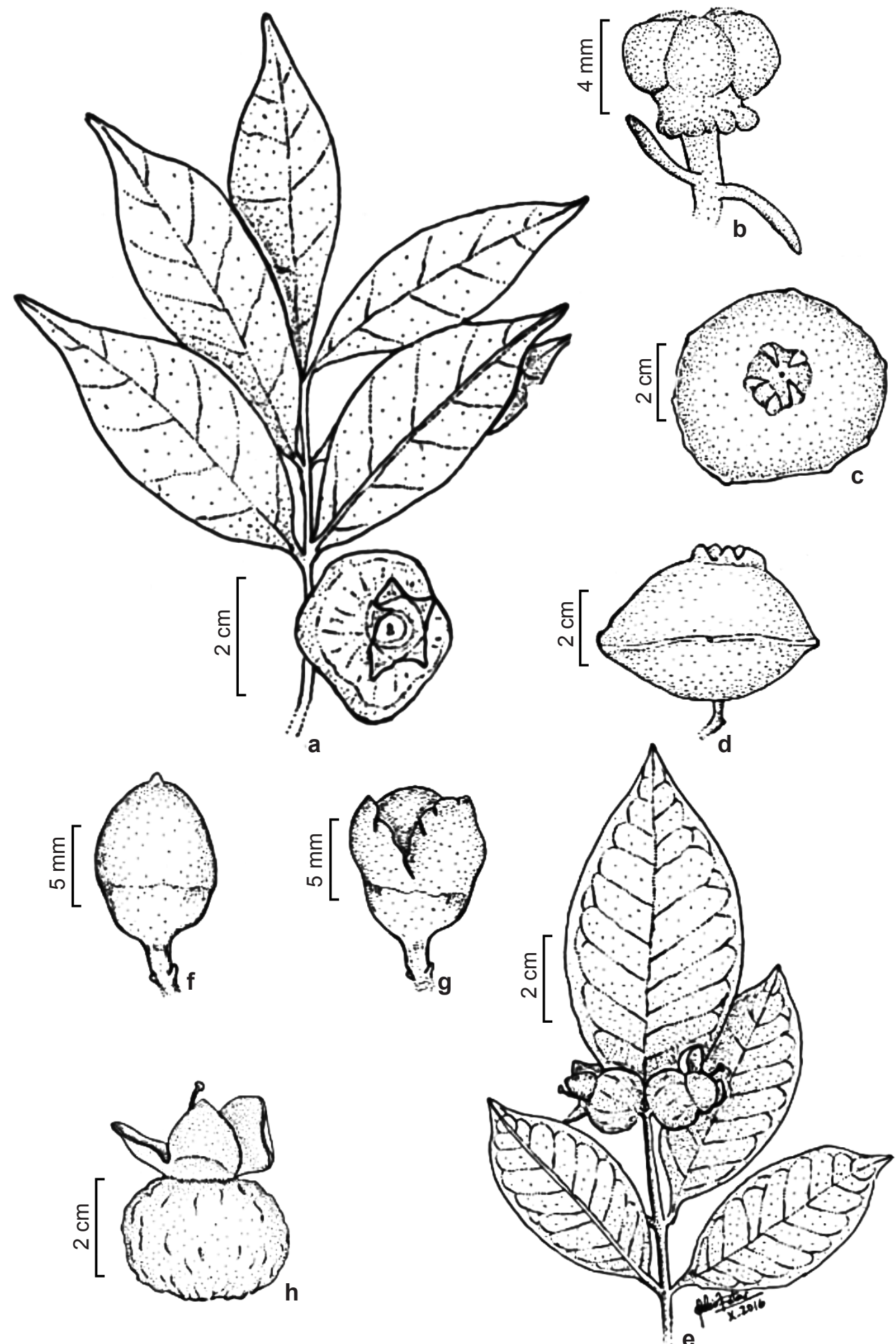

Figura 4 - a-d. Campomanesia phaea - a. variação na forma da folha; b. botão floral; c,d. fruto maduro. e-h. $C$. schlechtendaliana - e. formato da folha; f. botão floral apiculado; g. sépalas com abertura irregular; h. fruto levemente rugoso. (a-d. J. Luber 217; f,g. J. Luber 204; e,h. J. Luber 202).

Figure 4 - a-d. Campomanesia phaea - a. leaf shape variation; b. floral bud; c,d. shape fruit mature. e-h. C. schlechtendaliana - e. leaf shape variation; f. flower bud apiculate; g. sepals with irregular opening; h. fruit slightly rugose. (a-d. J. Luber 217 ; f,g.J. Luber 204; e,h. J. Luber 202). 
raro concolor, lustrosa ou opaca na face abaxial e na face adaxial; domácias no encontro da nervura secundária com a primária presentes; 4-8 pares de nervuras secundárias, proeminentes na face abaxial e impressas na face adaxial, glabra ou pilosa. Inflorescência unifloras. Flores com pedicelo 3,5-23,1 × 0,4-11 mm, glabro ou piloso, raro não glanduloso; brácteas não observadas; bractéolas 1,2-3 × 0,2-0,7 mm, sésseis, lineares, cartáceas, não persistentes no fruto; botão 4,5-7,4 × 4,5-7,7 $\mathrm{mm}$, cálice com abertura regular na antese, não apiculado; (4-)5-sépalas, 1,7-2 × 2-4,8 mm, regulares, cartáceas, deltoides, face interna pilosa, não glandular, face externa pilosa, glandular; (4-)5-pétalas, 6,2-8 × 5,4-8 mm, glabra, glandular; estames 175-250; filete 2,8-13,4 mm compr., inserção basifixa, glândula terminal presente, raro ausente; antera com ápice arredondado 0,4-1,3 $\times$ 0,2-0,8 mm; estilete 2,2-5 mm compr.; disco floral côncavo a plano 2,7-5,7 mm diâm., glabro ou piloso, raro glanduloso; ovário 8-12 locular, 7-16 óvulos por lóculo, 1-2 lóculos desenvolvidos. Frutos 6,3-18,2 × 8,6-19,5 mm, epicarpo rígido quando maduro, globosos, glabros, vermelhos ou roxos quando maduros, lisos, sépalas persistentes inteiras no fruto. Sementes 3,1 $\times 1,5 \mathrm{~mm}$, elípticas, ca. 3 por fruto.

Material examinado: Águia Branca, 21.XII.2007, bot. e fl., V. Demuner 4866 (MBML). Anchieta, 1.II.2012, fr., N.E. Oliveira Filho e D.T. Wandekoken 03 (VIES). Aracruz, 23.VIII.1991, fr., $V$. de Souza 173 (CVRD). Conceição da Barra, 9.XII.1992, fr., O.J. Pereira e J.M.L. Gomes 4358 (VIES); 20.V.1999, fr., G. Hatschbach, J.M. Silva \& L.A. Ferreira 69208 (MBML). Linhares, 6.I.1994, fr., D.A. Folli 2151 (CVRD); 10.XI.1998, bot., D.A. Folli 3279 (CVRD); 12.XII.1989, fr., D.A. Folli 1020 (CVRD); 17.XI.1994, fr., D.A. Folli 2419 (CVRD); 19.II.2008, fr., D.A. Folli 5951 (CVRD); 22.XI.2004, bot. e fl., G.S. Siqueira 139 (CVRD). Santa Leopoldina, 19.I.2002, fr., L. Kollmann 5330 (MBML). Santa Teresa, 2.XII.1998, fr., L. Kollmann 1160 (MBML); 7.XI.2001, bot. e fl., L. Kollmann 5009 (MBML); 11.IV.2000, fr., V. Demuner 894 (MBML); 12.XI.1998, fr., L. Kollmann 976(MBML); 14.VIII.2001, bot., L. Kollmann 4327 (MBML); 14.VIII.2001, fr., L. Kollmann 4325 (MBML); 16.X.2001, bot., L. Kollmann 4853 (MBML); 16.XII.1999, fr., V. Demuner 362 (MBML); 19.XII.2002, fr., R.R. Vervloet 1573 (MBML); 23.I.1999, fr., $V$. Demuner 394 (MBML); 26.XI.1998, fr., L. Kollmann 1119 (MBML). São Roque do Canaã, 24.XII.2003, bot. e fl., A.P. Fontana 676 (MBML). Venda Nova do Imigrante, 1.II.1995, fr., D.A. Folli 2550 (CVRD). Vila Valério, 1.IX.2012, bot., A.M. Assis 3352 (MBML).

Campomanesia guaviroba ocorre na Argentina, Bolívia, Paraguai e no Brasil (Landrum
1986; Trópicos 2016). No Brasil, é conhecida para os estados da Amazônia, Bahia, Minas Gerais, São Paulo, Sergipe, Paraná, Santa Catarina, Rio Grande do Sul, Distrito Federal e Espírito Santo (Landim \& Landrum 2005; BFG 2015), permanecendo ainda sem avaliação quanto ao estado de conservação. No Espírito Santo foi encontrada tanto em ambientes preservados como alterados, de norte a sul do estado (Fig. 10b). Encontrada com botão de agosto a dezembro, flores novembro e dezembro, e frutos em agosto, e de novembro a maio.

Campomanesia guaviroba se assemelha a $C$. laurifolia quando encontradas estéreis. Ambas as espécies apresentam ampla variação morfológica nas folhas, sendo uma parte dessa variação similar entre elas (Fig. 3a,h), porém $C$. guaviroba apresentam domácias no encontro das nervuras secundárias com a primária (Fig. 3b), enquanto em $C$. laurifolia, estas são ausentes. Além disso, quando férteis estas apresentam diferenças principalmente no comprimento da antera e no fruto. Campomanesia guaviroba apresenta a antera arredondada (Fig. 3c), enquanto C. laurifolia possui antera com ápice agudo (Fig. 3k). Já os frutos em C. guaviroba são globosos e de superfície lisa, enquanto os frutos de C. laurifolia são globosos ou subglobosos e de superfície lisa ou rugosa.

6. Campomanesia guazumifolia (Cambess.) $\mathrm{O}$. Berg Linnaea 27:434. 1854.

Figs. 3e-g; 7e-g; 10b

Árvores de 15-21 m de alt. Folhas opostas dísticas com pecíolos 5,5-19,6 × 1,2-3,1 mm, canaliculado, piloso, glanduloso; lâminas 10,46-20,37 × 5,12-9,51 cm, cartáceas ou membranáceas, elípticas, ápice atenuado ou obtuso, base arredondada ou cuneada, superfície lisa, plana, discolor ou concolor, opaca ou lustrosa na face abaxial e na face adaxial; domácias no encontro da nervura secundária com a primária ausentes; 11-14 pares de nervuras secundárias, proeminentes na face abaxial, impressas na face adaxial, pilosas. Inflorescência unifloras. Flores com pedicelo 13,1-15,1 × 2-2,5 mm, piloso, glanduloso; brácteas e bractéolas não observadas; botão ca. 15,5 × 14,1 mm, cálice fusionado com abertura irregular na antese, apiculado; (4-)5-sépalas, 9,8-13,6 $\times$ 9,8-19,2 mm, regulares, cartáceas, deltoides, face interna pilosa ou glabra, glandular ou não, face externa pilosa, glandular ou não; 5-pétalas, ca. 33,7 × $26 \mathrm{~mm}$, glabra, glandular; estames não quantificados; filete ca. $19 \mathrm{~mm}$ compr., inserção basifixa, glândula terminal ausente; antera com 

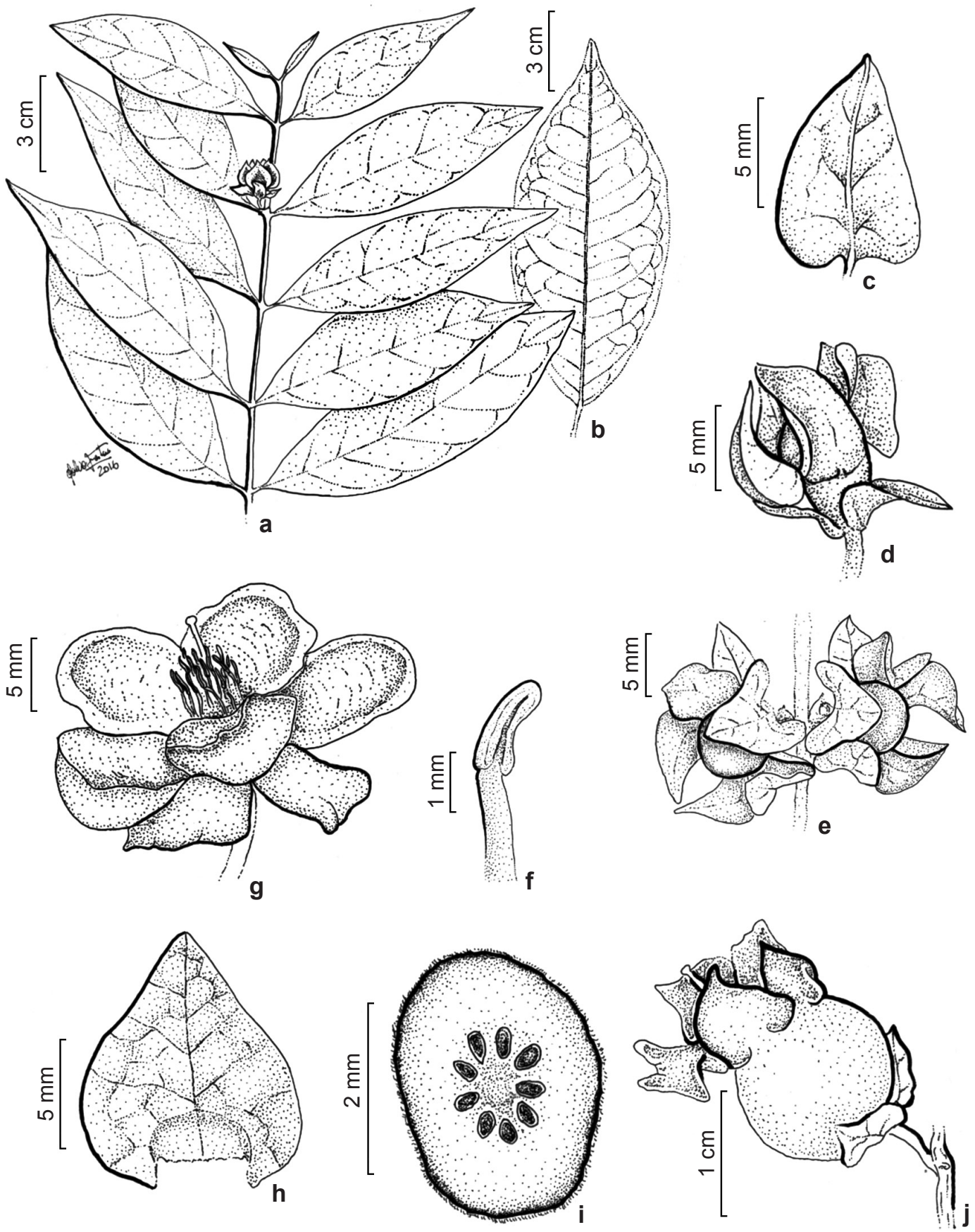

Figura 5 - a-j. Campomanesia sepalifolia - a. ramo com posição das folhas; b. detalhe da lâmina foliar, tamanho, forma e venação; c. bractéola desenvolvida; d. botão floral com bractéolas desenvolvidas e sépalas folhosas; e. botão floral; f. antera com ápice agudo; g. flor; h. sépala folhosa com base cordiforme; i. ovário multilocular; j. fruto imaturo com bractéolas persistente e sépalas folhosas com base cordiforme. (a,b,d,e. J. Luber 224; c,h,j. J. Luber 230; f,g,i. J. Luber 277).

Figure 5 - a-j. Campomanesia sepalifolia - a. branch tip; b. detail of leaf blade size, shape and type of venation; c. bracteole developed; d. floral bud with bracteoles developed and sepals foliaceous; e. floral bud; f. anther with acute apide; g. flower; h. sepals foliaceous with cordiform base; i. multilocular ovary; j. immature fruit with bracteoles persistent and sepals foliaceous with cordiform base. (a,b,d,e. $J$. Luber 224; c,h,j. J. Luber 230; f,g,i. J. Luber 277). 
ápice arredondado ca. 1,9 × 0,4 mm; estilete 5-18 mm compr.; disco floral côncavo a plano 14,2-16,5 mm diâm., glabro ou piloso, não glanduloso; ovário ca. 11 locular, ca. 12 óvulos por lóculo, ca. 8 lóculos desenvolvidos. Frutos 2,62-3,55 × 2,86-4,05 cm, epicarpo não rígido quando maduro, globosos, pilosos, amarelos quando maduros, rugosos ou não, sépalas persistentes inteiras no fruto. Sementes não vistas.

Material examinado: Íuna, 12.XI.2015, bot., fl. e fr., J.P.R. Zorzanelli 1360 (VIES). Santa Teresa, 10.IV.2003, fr., R.R. Vervloet 2195 (MBML).

Campomanesia guazumifolia ocorre na Argentina, Paraguai e Brasil (Trópicos 2016), sendo conhecida no último país para os estados da Bahia, Minas Gerais, Rio de Janeiro, São Paulo, Paraná, Rio Grande do Sul, Santa Catarina e Espírito Santo (BFG 2015), permanecendo ainda sem avaliação quanto ao estado de conservação (BFG 2015). No Espírito Santo a espécie foi encontrada em regiões montanhosas ao sul do estado, e em áreas próximas à vegetação florestal (Fig. 10b). Encontrada com fruto nos meses de abril e novembro, e com botão e flor no mês de novembro.

Campomanesia guazumifolia assemelha-se com C. schlechtendaliana por apresentar o cálice fechando com o ápice do botão apiculado (Figs. 3f; 4f) e sépalas que se abrem irregularmente na antese. No entanto, C. guazumifolia é encontrada em região de montanha e caracteriza-se morfologicamente por apresentar porte arbóreo, podendo chegar até a 21 $\mathrm{m}$ de altura (Fig. 7e), possui ritidoma descamando em placas irregulares (Fig. 7f), além de apresentar lâminas foliares maiores (Fig. 3e) (de 10,46-20,37 $\times 5,12-9,51 \mathrm{~cm}$ e não de 4,76-12,59 × 2,79-5,25 $\mathrm{cm}$ ) e mais pilosas, e os frutos rugosos (Fig. $3 \mathrm{~g}$ ) ou pilosos.

7. Campomanesia laurifolia Gardner, London Journal of Botany 2: 353. 1843.

Figs. 3h-k; 7h,i; 10b

Árvores ou arbustos de $2-10 \mathrm{~m}$ de alt. Folhas opostas dísticas com pecíolos 3-17,8 $\times$ 0,7-5,3 mm, canaliculado, piloso, glanduloso; lâminas 6,46-17,6 × 2,51-6,53 cm, cartáceas, elípticas, ápice acuminado, agudo ou atenuado, base cuneada, superfície lisa, plana, discolor, raro concolor, opaca, raro lustrosa na face abaxial e na face adaxial; domácias no encontro da nervura secundária com a primária ausentes; 5-12 pares de nervuras secundárias, proeminentes na face abaxial e impressas na face adaxial, pilosas, raro glabras. Inflorescência unifloras ou em dicásios 3-floros, eixo da inflorescência de 1,06-2 cm compr. Flores com pedicelo 3,1-25,3 × 0,7-1,9 mm, piloso, glanduloso; brácteas 3-13,1 × 0,5-3 mm, sésseis, elípticas ou lanceoladas, cartáceas; bractéolas não observadas; botão 5,9-18,6 × 5,9-14,1 mm, cálice com abertura regular na antese, não apiculado; 5-sépalas, 4,4-13,9 × 3,3-9,1 mm, regulares, cartáceas ou membranáceas, deltoides, face interna pilosa, não glandular, face externa pilosa, glandular; 5-pétalas, ca. 13,3 × 10,9 mm, pilosa, glandular; estames não quantificados; filete 5-5,7 mm compr., inserção basifixa, glândula terminal presente; antera com ápice agudo 1,9-2 × 0,2-6 mm; estilete ca. 9,3 mm compr.; disco floral côncavo a plano 8,3-9,1 mm diâm., glabro ou piloso, não glanduloso; ovário 5-8 locular, ca. 10 óvulos por lóculo, 5-8 lóculos desenvolvidos. Frutos 20,4-42,6 × 15,2-38,6 $\mathrm{mm}$, epicarpo rígido quando maduro, globosos ou subglobosos, glabros ou pilosos, amarelos quando maduros, lisos ou rugosos, sépalas persistentes inteiras no fruto. Sementes $6,1-11,3 \times 3,2-8,8 \mathrm{~mm}$, elípticas, ca. 3 por fruto.

Material examinado: Águia Branca, 16.VIII.2007, fr., R.R. Vervloet 3219 (MBML). Aracruz, 30.VI.2013, fr., R.N. Oliveira 556 (VIES). Cachoeiro de Itapemirim, 24.I.2011, fl., P. Fiaschi 3563 (VIES). Cariacica, 6.V.2008, fr., R. Goldenberg 1120 (MBML); 22.VII.2008, fr., A.M.A. Amorim 7637 (MBML); 7.I.2009, bot. e fl., D.A. Folli 6268 (CVRD); 12.I.2007, bot., D.A. Folli 5447 (CVRD); 17.VI.2009, fr., G.S. Siqueira 466 (CVRD); 20.IV.2016, fr., J. Luber et al 233 (VIES). Pancas, 8.VII.2015, fr,, J. Luber et al. 154 (VIES). Santa Leopoldina, 9.VIII.2006, fr., L.F.S. Magnago 1245 (MBML); 9.VIII.2006, fr., L.F.S. Magnago 1245 (MBML); 14.IV.2008, fr., L. Kollmann, A.P. Fontana e K. Brahim 10833 (MBML); 18.VIII.1998, fr., L. Kollmann et al. 385 (VIES); 29.I.2008, fr., V. Demuner, T.A. Cruz e M. Belisario 4923 (MBML); 29.VI.2006., fr., V. Demuner 2504 (MBML). Santa Teresa, 5.IX.2003, bot., J. Rossini 535 (MBML); 9.I.2002, fr., L. Kollmann 5247 (MBML); 9.I.2003, fr., R.R. Vervloet 1678 (MBML); 10.XI.1998, bot., L. Kollmann 966 (MBML); 12.IX.2000, fr., $V$. Demuner 1377 (MBML); 13.IX.2006, fr., R. Marquete 3899 (MBML); 16.XII.1998, fr., L. Kollmann 1334 (MBML); 18.II.2003, bot. e fr., R.R. Vervloet 1852 (MBML); 20.II.2002, fr., L. Kollmann 5599 (MBML); 21.V.2003, fr., R.R. Vervloet 2470 (MBML); 22.IV.2003, fr., R.R. Vervloet 2271 (MBML); 23.X.2001, bot., L. Kollmann 4886 (MBML); 29.VIII.2001, fr., L. Kollmann 4394 (MBML); 30.XI.2000, fr., V. Demuner 1574 (MBML); 8.VIII.2000, fr., V. Demuner 1361 (MBML). São Gabriel da Palha, 26.IV.2008, fr., A.M. Assis 1542 (MBML). Serra, 23.VII.2010, fr., R.S. Cribari (VIES). Vargem Alta, 26.VI.2012, fr., D.A. Folli 6873 (CVRD). Vitória, 14.V.2003, fr., O.J. Pereire 7153 (VIES); 27.XII.2002, fr., O.J. Pereira e Y.S. de Deus 7066 (VIES). 


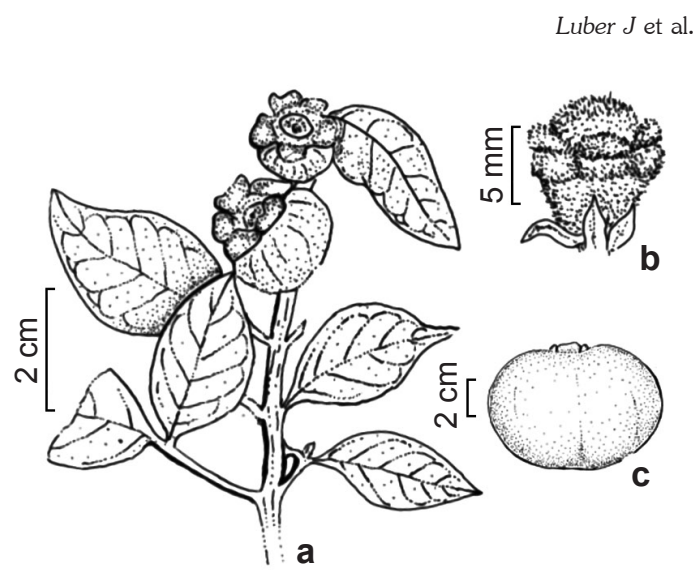

Campomanesia laurifolia é endêmica do Brasil, tendo registro para os estados da Bahia, Minas Gerais, Rio de Janeiro e Espírito Santo (BFG 2015), sendo categorizada como pouco preocupante (LC) quanto ao estado de conservação (BFG 2015). No Espírito Santo, essa espécie apresenta ampla distribuição (Fig. 10b), sendo encontrada em formações florestais, matas ciliares, áreas em regeneração e beira de estradas. Fértil na maior parte do ano, com botão de setembro a novembro, e em janeiro e fevereiro, com flor em dezembro e janeiro, e com fruto de abril a setembro e de novembro a fevereiro.

Quando estéril, C. laurifolia assemelha-se a $C$. guaviroba e a $C$. sepalifolia. Campomanesia guaviroba (Fig. 3a) e C. laurifolia (Fig. 3h) apresentam ampla variação morfológica nas folhas, sendo uma parte dessa variação compartilhada entre elas. No entanto, C. laurifolia não apresenta domácias no encontro das nervuras secundárias com a primárias, enquanto em $C$. guaviroba estas estão presentes. Além desta característica, C. laurifolia e C. guaviroba se diferenciam pela morfologia das anteras e dos frutos. Campomanesia laurifolia apresenta a antera com ápice agudo (Fig. 3k), enquanto C. guaviroba apresenta antera arredondada. Já os frutos em $C$. laurifolia apresentam a superfície lisa ou rugosa e os frutos globosos ou subglobosos, enquanto os frutos de C. guaviroba apresentam a superfície lisa e formato globoso (Fig. 3j; 7i). Campomanesia laurifolia difere de $C$. sepalifolia por apresentar brácteas com 3-13,1 × 0,5-3 mm (não de 8,1-15,2 $\times 5,3-12,8)$, não persistentes no fruto, além das sépalas não possuírem a base cordiforme como em C. sepalifolia.

8. Campomanesia macrobracteolata Landrum, Brittonia 53(4): 534-536, f. 1. 2002.

Figs. 31-s; 8a-c; 10c

Árvores ou arbustos de $2-22 \mathrm{~m}$ de alt. Folhas opostas dísticas com pecíolos 5,2-16,8 × 0,9-2,9 $\mathrm{mm}$, canaliculado, piloso, glanduloso ou não; lâminas 4,01-13,09 × 3,18-8,57 cm, cartáceas ou coriáceas, elípticas, largo-elípticas, obovadas ou ovadas, ápice atenuado, arredondado, cuneado, cuspidado ou obtuso, base arredondada, cuneada, ou truncada, superfície lisa, plana, discolor, raro concolor, lustrosa ou opaca na face abaxial e na face adaxial; domácias no encontro da nervura secundária com a primária ausente; 4-7 pares de nervuras secundárias, proeminentes na face abaxial e impressas na face adaxial, pilosas.

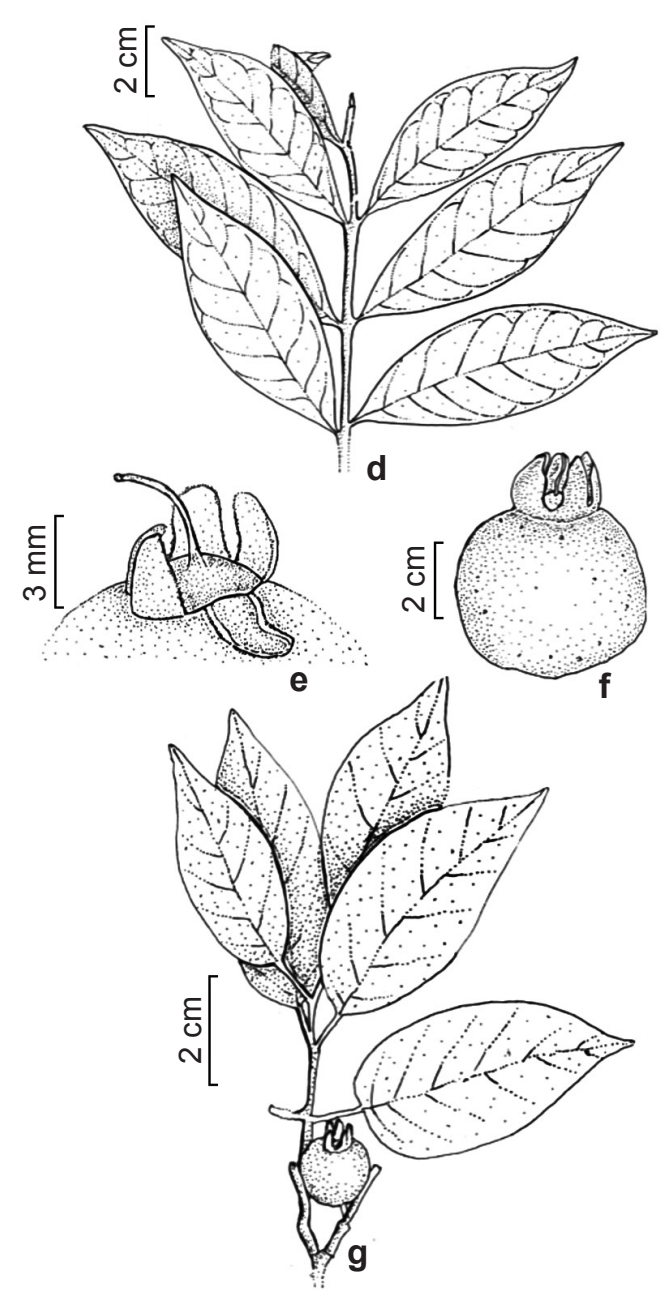

Figura 6 - a-d. Campomanesia sessiliflora - a. fruto imaturo; b. botão floral; c. fruto maduro; $d$. forma das folhas. e-g. C. xanthocarpa - e. disco floral convexo; f. fruto maduro; g. forma das folhas. (a-d. A.P. Fontana 3142; e-g. D.A. Folli 6756).

Figure 6 - a-d. Campomanesia sessiliflora - a. fruit imature; b. flower bud; c. fruit mature; d. leaf shape. e-g. C. xanthocarpae. floral disc prominent; f. fruit mature; g. leaf shape. (a-d. A.P. Fontana 3142; e-g. D.A. Folli 6756). 
Inflorescência unifloras ou dicásio 3-floros, eixo da inflorescência de 9-61,4 mm. Flores com pedicelo 5,4-36,1 × 0,5-1,6 mm, glabro ou piloso, glanduloso; brácteas $3,1-15,3 \times$ 0,4-9 mm, sésseis ou pecioladas 1,2-3,9 $\mathrm{mm}$ de compr., elípticas, lanceoladas ou ovadas, cartáceas ou membranáceas; bractéolas 4-5 × 0,8-1,9 mm, sésseis ou pecioladas 1-2 mm de compr., elípticas, cartáceas, persistente ou não nos frutos; botão $6,1-10,8 \times 5,2-7,8 \mathrm{~mm}$, cálice com abertura regular na antese, não apiculado; 5-sépalas, 3,2-12,3 × 3,4-8 mm, regulares, cartáceas ou membranáceas, arredondadas, deltoides ou elípticas, face interna pilosa, glandular ou não, face externa pilosa, glandular ou não; 5-pétalas, 9-13 × 8,2-11,2 mm, glabra ou pilosa, glandular; estames 150-270; filete 2,2-6 mm compr., inserção basifixa, glândula terminal presente; antera com ápice arredondado, 0,8-1 × 0,3-0,8 mm; estilete 3-13 mm compr.; disco floral côncavo a plano 3,8-7 mm diâm., piloso, não glanduloso; ovário 5-8 locular, ca. 9 óvulos por lóculo, 1-3 lóculos desenvolvidos. Frutos 10,4-23,4 × 10,1-28,5 mm, epicarpo rígido quando maduro, globosos, pilosos, amarelos quando maduros, ornamentados ou não com protuberâncias cilíndricas desenvolvidas (verrucoso), quando lisos com glândulas muito visíveis, sépalas persistentes inteiras no fruto. Sementes 6-11,2 × 1,4-4,7 mm, elípticas, 2-8 por fruto.

Material examinado: Guarapari, 14.XII.1998, bot., A.M. Assis et al. 674 (VIES). Itapemirim, 18.X.1991, fr., V. de Souza 228 (CVRD); 29.XII.2007, fr., A.M. Assis et al. 1295 (MBML); 15.III.2008, fr., A.M. Assis et al. 1445 (MBML). Linhares, 7.XII.1988, bot. e fl., D.A. Folli 826 (CVRD); 7.III.1994, fr., D.A. Folli 2235 (CVRD); 3.II.1997, fr., D.A. Folli 2913 (CVRD); 26.III.2008, fr., D.A. Folli 5996 (CVRD); 10.I.2009, fl., D.A. Folli 6281 (CVRD); 30.XI.2010, bot. e fl., D.A. Folli 6748 (CVRD); 20.IV.2016, fr., J. Luber, A.C. Tuler \& H.P. Junior 232 (VIES); 20.IV.2016, fr., J. Luber, A.C. Tuler \& H.P. Junior 231 (VIES). Presidente Kennedy, 27.IV.1997, fr., O.J. Pereira 5808 (VIES); 21.IV.2009, bot., A.M. Assis \& M.D.S. Demuner 2028 (MBML); 30.XI.2013, bot. e fl., G.S. Siqueira 919 (CVRD); 30.XI.2013, fr., G.S. Siqueira 920 (CVRD); 4.II.2016, fr., J. Luber, A.C. Tuler \& T.T. Carrijo 216 (VIES); 4.II.2016, fr., J. Luber, A.C. Tuler \& T.T. Carrijo 214 (VIES); 4.II.2016, fr., J. Luber, A.C. Tuler \& T.T. Carrijo 212 (VIES); 4.II.2016, fr., J. Luber, A.C. Tuler \& T.T. Carrijo 213 (VIES); 4.II.2016, fr., J. Luber, A.C. Tuler \& T.T. Carrijo 215 (VIES).

Campomanesia macrobracteolata é endêmica do Brasil, tendo registro para os estados do Rio de Janeiro e Espírito Santo. Essa espécie foi categorizada como vulnerável (VU) (BFG 2015). No Espírito Santo, a espécie foi encontrada em vegetação aberta e arbórea de restinga ao sul do estado e em floresta de tabuleiro ao norte (Fig. 10c). Coletada com botão em abril, novembro e dezembro, com flores de novembro a janeiro, e com frutos de outubro a abril.

Campomanesia macrobracteolata assemelha-se com $C$. anemonea pelo formato das folhas, pelas flores ocasionalmente em dicásio e pelo fruto ornamentado (Fig. 31). $\mathrm{Na}$ ornamentação de $C$. macrobracteolata são observadas glândulas, que podem se desenvolver formando protuberâncias cilíndricas ou não (Fig. 31,o,q,s). Quando as glândulas não se desenvolvem, estas são observadas facilmente no fruto, mesmo sendo liso (Fig. 8c), diferente de $C$. anemonea que apresenta tricomas ao invés de glândulas. Ambas as espécies ocorrem em restinga (Figs. 8b; 10a,c). No entanto, apenas $C$. macrobracteolata ocorre em floresta de tabuleiro (Figs. 8a; 10c).

A altura conhecida da espécie, antes descrita em até $3 \mathrm{~m}$, foi ampliada para $22 \mathrm{~m}$. Os indivíduos mais altos foram encontrados em floresta de tabuleiro. As bractéolas possuem grande variação de tamanho (3,1-15,3 ×0,4-9 mm). Já as sépalas, podem ser membranáceas e grandes ou cartáceas e pequenas (Fig. 31,o,q,s). A ornamentação dos frutos não foi mencionada em sua descrição original, mas a análise de indivíduos em campo possibilitou a observação de que estes podem ser lisos ou ornamentados, sendo observado um gradiente entre essas condições, por vezes presente no mesmo indivíduo. As folhas também são bastante variáveis quanto à consistência e formato (Fig. 3m,n,p,r).

9. Campomanesia phaea (O.Berg) Landrum, Brittonia 36(3): 241. 1984. Figs. 4a-d; 8d-f; 10c Árvores de 7-10 m de alt. Folhas opostas cruzadas com pecíolo 3,9-7 × 0,7-1,4 mm, canaliculado ou cilíndrico, piloso, glanduloso; lâminas 3,26-7,88 × 1,79-2,61 cm, cartáceas, elípticas ou lanceoladas, ápice agudo ou cuneado, base cuneada, superfície lisa, plana, discolor, lustrosa na face abaxial e na face adaxial; domácias no encontro da nervura secundária com a primária ausentes; 5-8 pares de nervuras secundárias, impressas ou proeminentes na face abaxial e impressas ou inconspícuas na face adaxial, glabras ou pilosa. Inflorescência 

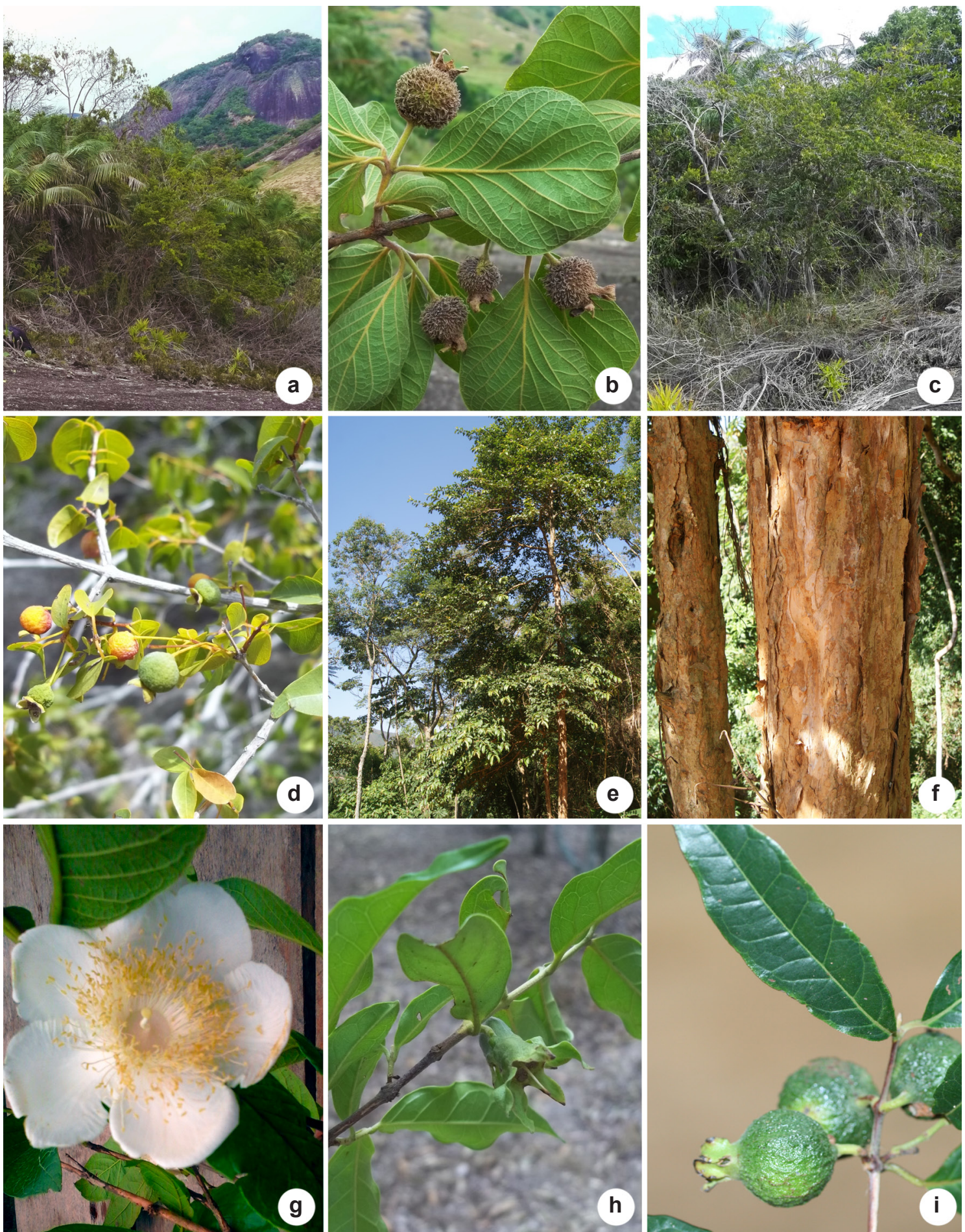

Figura 7 - a,b. Campomanesia anemonea - a. hábito; b. fruto. c,d. C. eugenioides - c. hábito; d. fruto. e-g. C. guazumifolia - e. hábito; f. ritidoma; g. flor. h,i. C. laurifolia - h. ovário em desenvolvimento; i. fruto.

Figure 7 - a,b. Campomanesia anemonea - a. habit; b. fruit. c,d. C. eugenioides - c. habit; d. fruit. e-g. C. guazumifolia - e. habit; f. rhytidoma; g. flower. h,i. C. laurifolia - h. developing ovary; i. fruit. 
unifloras. Flores com pedicelo 2,4-9,1 × 1-2,5 $\mathrm{mm}$, piloso, glanduloso; brácteas ca. 9,2 × 1,9 mm, sésseis, lanceoladas, membranáceas; bractéolas não observadas; botão ca. 5,1 × $6 \mathrm{~mm}$, cálice com abertura regular na antese, não apiculado; 5-sépalas, 3,2-6,1 × 2,9-7,1 mm, com divisões bem definidas formando conchas e uma bainha logo abaixo da inserção; cartáceas, deltoides, face interna pilosa, não glandular, face externa glabra ou pilosa, glandular ou não; 5-pétalas, tamanho não mensurado, glabra, não glandular; estames ca. 200; filete ca. 0,6 mm compr., inserção basifixa, glândula terminal presente; antera com ápice arredondado ca. $0,7 \times 0,3 \mathrm{~mm}$; estilete ca. 2 mm compr.; disco floral côncavo a plano 3,7-8,8 mm diâm., piloso, não glanduloso; ovário 10-13 locular, ca. 10 óvulos por lóculo, ca. 4 lóculos desenvolvidos. Frutos 17,9-34,8 × 28,2-40,5 mm, epicarpo não rígido quando maduro, discoides, glabros ou pilosos, verdes quando maduros, lisos, sépalas persistentes inteiras no fruto. Sementes 3,1 $\times 1,5 \mathrm{~mm}$, elípticas, ca. 6 por fruto.

Material examinado: Domingos Martins, 4.III.2016, bot. e fr., J. Luber \& D.F. Luber 218 (VIES); 4.III.2016, bot. e fr., J. Luber \& D.F. Luber 217 (VIES). Santa Teresa, 10.VIII.2000, fr., V. Demuner, E. Bausen \& E. Pizziolo 1365 (MBML).

Campomanesia phaea é endêmica do Brasil, tendo registro para os estados de Minas Gerais, Rio de Janeiro e São Paulo (BFG 2015), sendo um novo registro para o Espírito Santo (Fig. 10c) e estando categorizada como pouco preocupante (LC) quanto ao estado de conservação (BFG 2015). Encontrada no Espírito Santo, sempre como uma cultivar (Fig. 8e) devido aos seus frutos grandes e comestíveis despertarem interesse para a produção de sucos e geleias, sendo uma espécie potencial para o desenvolvimento de trabalhos de melhoramento genético. Encontrada com botão em março e com fruto em março e agosto.

Campomanesia phaea assemelhasse-se com C. sessiliflora, pela filotaxia oposta cruzadas, lanceoladas e diminutas, e pelos frutos grandes com epicarpo não rígido quando maduro. No entanto, o ritidoma de $C$. phaea descama longitudinalmente (não em placas irregulares), as flores possuem pedicelos de 2,4-9,1 × 1-2,5 cm (não ca. de 0,5 $\times 0,6 \mathrm{~cm}$ ou séssil). No botão floral as sépalas apresentam divisões bem definidas, cuculadas (formando conchas) e uma bainha logo abaixo da inserção das sépalas (Figs. 4b; 8d), enquanto que em $C$. sessiliflora a divisão das sépalas no botão não é claramente distinguível, apresentando um ápice levemente recurvado para trás, com ausência da bainha. Os frutos de C. phaea apresentam um formato discoide (Figs. 4c,d; 8f), diferente de $C$. sessiliflora, na qual os frutos são globosos.

10. Campomanesia schlechtendaliana (O.Berg) Nied., in Engler \& Prantl, Nat. Pflanzenfam. 3(7):73. 1893. Figs. 4e-h; 8g,h; 10c

Árvores ou arbustos, de 2-8 m de alt. Folhas opostas dísticas com pecíolo 2,8-9,9 × 0,7-2,1 $\mathrm{mm}$, canaliculado, piloso, glanduloso ou não; lâminas 4,76-12,59 × 2,79-5,25 cm, cartáceas ou membranáceas, elípticas, ápice agudo, atenuado, cuneado ou obtuso, base arredondada, cuneada ou obtusa, superfície lisa, plana ou revoluta, discolor ou concolor, opaca ou lustrosa na face abaxial e lustrosa na face adaxial, domácias no encontro da nervura secundária com a primária ausentes; 8-13 pares de nervuras secundárias, proeminentes na face abaxial e impressas na face adaxial, pilosas. Inflorescência unifloras. Flores com pedicelo $1,5-7,1 \times 0,5-1,9 \mathrm{~mm}$, piloso, raro glanduloso; brácteas $3,2-5 \times$ ca. $1 \mathrm{~mm}$, sésseis, lanceoladas, cartáceas; bractéolas 1,8-4 × 0,9-1,1 $\mathrm{mm}$, sésseis, deltoides ou lanceoladas, cartáceas, não persistentes nos frutos; botão 6,6-12,9 × 5,1-10,9 mm, cálice fusionado com abertura irregular na antese, apiculado; 3-4-(-5)-sépalas, 4,1-12,7 × 4,2-17,3 mm, regulares, cartáceas, deltoides ou oblongas, face interna pilosa ou glabra, não glandular, face externa pilosa, glandular ou não; 5-pétalas, 11-19,5 × 10-14,5 mm, glabra ou pilosa, glandular; estames 320-560; filete 4,8-9,3 mm compr., inserção basifixa, glândula terminal presente; antera com ápice arredondado 1,3-2 $\times$ 0,3-0,7 mm; estilete 3-14,7 mm compr.; disco floral côncavo a plano 5,7-10 mm diâm., piloso, não glanduloso; ovário 7-14 locular, 10-18 óvulos por lóculo, 1-9 lóculos desenvolvidos. Frutos não mensurado, epicarpo rígido quando maduro, globosos, pilosos, liso, sépalas persistentes inteiras no fruto. Sementes não vistas.

Material examinado: Conceição da Barra, Parque Estadual de Itaúnas, 15.XII.2015, bot., J. Luber, R. Ferreira \& W. Oliveira 186 (VIES); bot., J. Luber, R. Ferreira \& W. Oliveira 188 (VIES); bot., J. Luber, R. Ferreira \& W. Oliveira 189 (VIES). Guarapari, 31.VII.1990, fl., O.J. Pereira \& J.M.L. Gomes 2180 (VIES); 14.XII.2015, bot. e fl., J. Luber, R. Ferreira \& W. Oliveira 184 (VIES); 28.I.2016, fl. e fr., J. Luber et al. 201(VIES); fr., J. Luber et al. 202 (VIES); bot., J. Luber et al. 200 (VIES). Itapemirim, 4.II.2016, fr., J. Luber, A.C. Tuler \& T.T. Carrijo 209 (VIES); bot. e fl., J. Luber, A.C. Tuler \& T.T. Carrijo 207 (VIES); fr., J. 

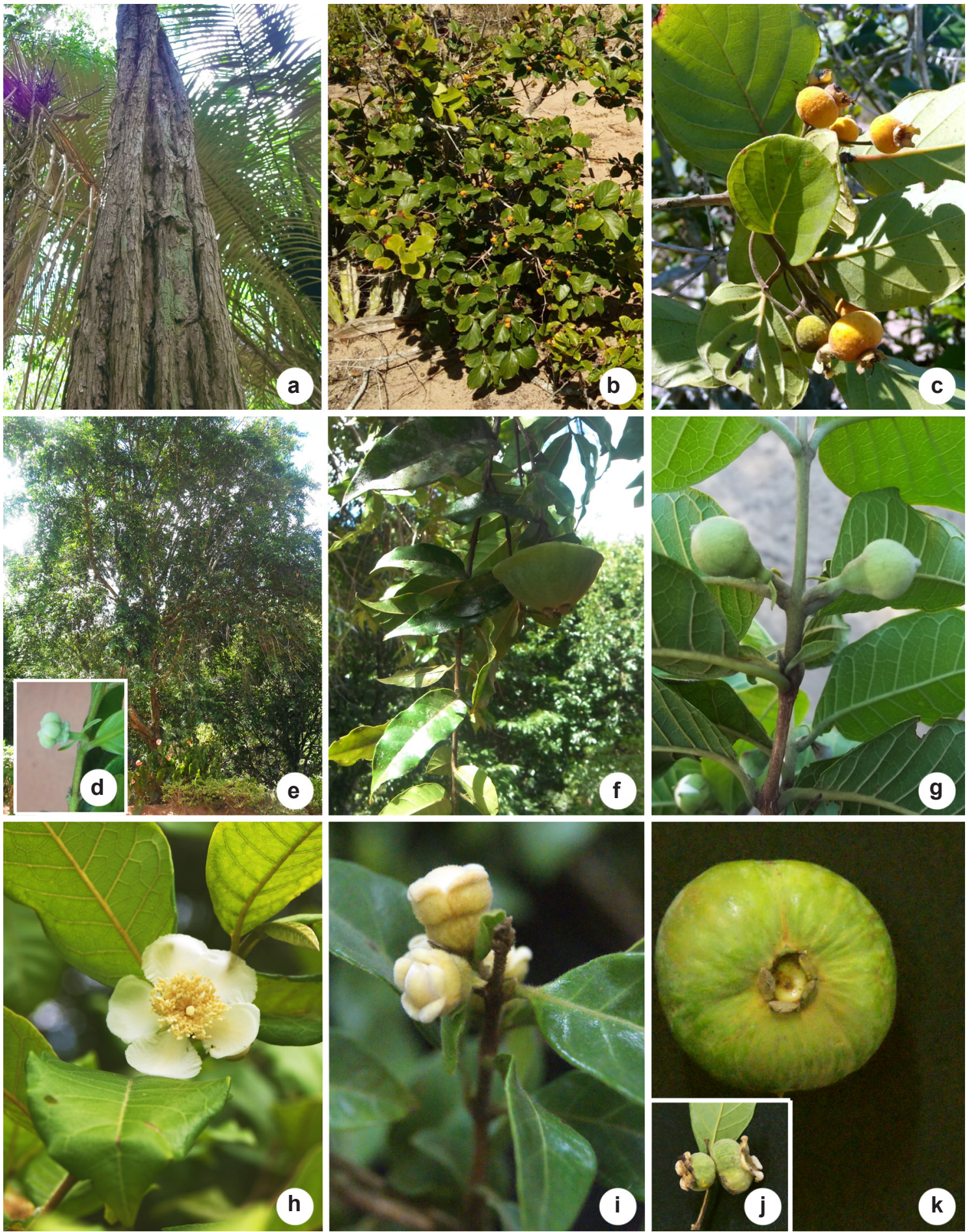

Figura 8 - a-c. Campomanesia macrobracteolata - a. hábito (floresta de tabuleiro); b. hábito (vegetação de restinga); c. fruto. d-f. C. phaea - d. botão floral; e. hábito; f. fruto. g,h. C. schlechtendaliana - g. botão floral; h. flor. i-k. C. sessiliflora $-\mathrm{i}$. botão floral; $\mathrm{j}$. fruto imaturos; $\mathrm{k}$. fruto maduro.

Figure 8 - a-c. Campomanesia macrobracteolata - a. habit (tabuleiro forest); b. habit (restinga vegetation); c. fruit. d-f. C. phaea - d. flower bud; e. habit; f. fruit. g,h. C. schlechtendaliana - g. flower bud; h. flower. i-k. C. sessiliflora - i. flower bud; j. imature fruits; k. mature fruit. 
Luber, A.C. Tuler \& T.T. Carrijo 211 (VIES); fr., J. Luber, A.C. Tuler \& T.T. Carrijo 208 (VIES); fr., J. Luber, A.C. Tuler \& T.T. Carrijo 210. Linhares, 7.XII.1988, bot. e fl.; D.A. Folli 824 (CVRD); 22.V.1989, bot., G.L. Farias 275 (CVRD); 26.IV.1994, fr., D.A. Folli 2295 (CVRD); 23.XI.2001, bot., D.A. Folli 4126 (CVRD); 29.X.2003, bot. e fl., G.S. Siqueira 55 (CVRD); 17.IV.2013, bot., fl. e fr., D.A. Folli 7053 (CVRD); 20.IV.2016, fr., J. Luber, A.C. Tuler \& H.P. Júnior 234 (VIES). Vila Velha, 22.V.1996, fl. e fr., O. Zambom \& H.Q.B. Fernandes 284 (VIES); 1.IX.2014, fr., R.T. Valadares \& D. Koski 1193 (VIES); 29.I.2016, fl., J. Luber, et al. 204 (VIES); bot. e fl., J. Luber et al. 203 (VIES). Vitória, 4.V.1990, bot. e fl., P. Vinha 815 (VIES); 28.XI.1997, bot. e fl., A.M. Assis \& I. Weiler Júnior 303 (VIES).

Campomanesia schlechtendaliana é endêmica do Brasil, tendo registro para os estados da Bahia, Minas Gerais, Rio de Janeiro, Espírito Santo, São Paulo e Paraná (BFG 2015), sendo categorizada como pouco preocupante (LC) (BFG 2015). Campomanesia schlechtendaliana foi encontrada em formações de restingas arbórea de norte a ao sul do estado, e em floresta de tabuleiro ao norte (Fig. 10c). Encontrada com botão (Fig. $8 \mathrm{~g}$ ) de outubro a fevereiro e em abril, com flor de outubro a fevereiro, abril e maio, e com fruto de dezembro a fevereiro, abril, maio e setembro.

Campomanesia schlechtendaliana assemelha-se com C. guazumifolia por apresentar o cálice fechando na antese, com o ápice do botão apiculado (Figs. 3f; 4f; 8g), e sépalas que se abrem irregularmente (Fig. 4g). No entanto, $C$. schlechtendaliana ocorre em ambientes de restinga e floresta de tabuleiro, geralmente apresentando hábito arbustivo. Quando apresenta hábito arbóreo, a altura dos indivíduos não ultrapassa 8 $\mathrm{m}$. Caracteriza-se morfologicamente pelo ritidoma descamando em placas longitudinais, folhas de 4,76-12,59 × 2,79-5,25 cm (Fig. 4e), ou seja, menores em comparação à C. guazumifolia, e glabras a olho desarmado. Os frutos são lisos ou pouco rugosos (Fig. 4h).

11. Campomanesia sepalifolia Luber \& M. Ibrahim, sp. nov. Tipo: BRASIL. ESPÍRITO SANTO: Águia Branca, propriedade do Senhor Antoni Kiok "Woito". Fragmento próximo ao lago, 18 58'47.17'S, 4044'51.92'W, ca. $10 \mathrm{~m}$, 19.IV.2016, fr., J. Luber, A.C. Tuler, H.P. Junior 230 (holótipo: VIES; isótopos: ASE e RB).

Campomanesia sepalifolia is related to C. laurifolia Gardner by leaf blade size and shape, that shows well-marked adaxial venation, and by the fruit with rounded shape and elongated base. However, the new species differs from $C$. laurifolia by the foliaceous sepals that shows a subcordate base, and developed bracteoles persistent in the fruit.

Figs. 5a-j; 9a-f; 10d

Árvores ou arbustos, 2-10 m alt. Tronco com placas descamando longitudinalmente de coloração avermelhada; ramos acastanhados, glandulares e glabros. Folhas opostas dísticas com pecíolos 3,7-11,8 × 0,9-1,7 mm, canaliculados, pilosos e glandulosos; lâminas 9-15 × 3,7-6 cm, cartáceas, elípticas, ápice acuminado, base cuneada, superfície plana, margem inteira, discolor, lustrosa ou opaca na face abaxial e na face adaxial, domácias no encontro da nervura secundária com a primária ausentes; nervura primária impressa na face adaxial e proeminente na abaxial, glandular; 5-10 pares de nervuras secundárias, proeminentes na face abaxial e impressas na face adaxial, broquidródomas, pilosas. Inflorescências axilares, unifloras ou dicásios 3-floros. Flores com pedicelos 3,4-18,2 $\times$ 0,5-1,4 mm, pilosos, glandulosos; brácteas não observadas; bractéolas 8,1-15,2 × 5,3-12,8 $\mathrm{mm}$, sésseis, deltoides, cartáceas, persistentes no fruto; botões 7,6-10,7 × 4,8-7,6 mm, globosos, pilosso, glandulosos; cálice com abertura regular na antese, não apiculado, dialissépalo; 5-sépalas, 7-14 × 5,5-12 mm, cartáceas, cordiformes, face interna pilosa, geralmente glandulosa, face externa pilosa e glandulosa; 5-pétalas, 11,8 × 12,9 mm, membranáceas, obovadas, glabras, glandulosas; estames 190-250; filetes 2,2-2,6 mm compr.; inserção basifixa, glândula terminal presente; antera com ápice agudo 1,2-2 ×0,4-0,5 mm; estilete ca. 0,5 cm de compr.; disco floral côncavo a plano 5-8,9 mm diâm., glabro ou piloso, glanduloso ou não; ovário com 6-9 lóculos, 8-12 óvulos por lóculo, 3-5 lóculos desenvolvidos. Frutos jovens globosos, pilosos, não glandulosos, sépalas persistentes inteiras no fruto. Sementes não observadas.

Material examinado (parátipos): Águia Branca, 24.IV.2004, fr., A.M. Assis 1047 (MBML); 15.III.2006, bot., V. Demuner 1950 (MBML); 30.XI.2006, bot., L.F.S. Magnago 1679 (MBML); 22.XI.2007, bot., $V$. Demuner 4590 (MBML); 20.XII.2007, bot., V. Demuner 4845 (MBML); 17.III.2016, bot., J. Luber 224 (VIES); 19.IV.2016, fr., J. Luber 230 (VIES); 26.I.2017, bot. e fl., J. Luber 277 (VIES).

Etimologia: o epíteto da espécie se refere à textura e forma das sépalas, que são semelhantes às folhas. Está característica é raramente observada em Campomanesia.

Campomanesia sepalifolia assemelha-se a $C$. laurifolia pela forma elíptica das folhas (Figs. 5a,b; 

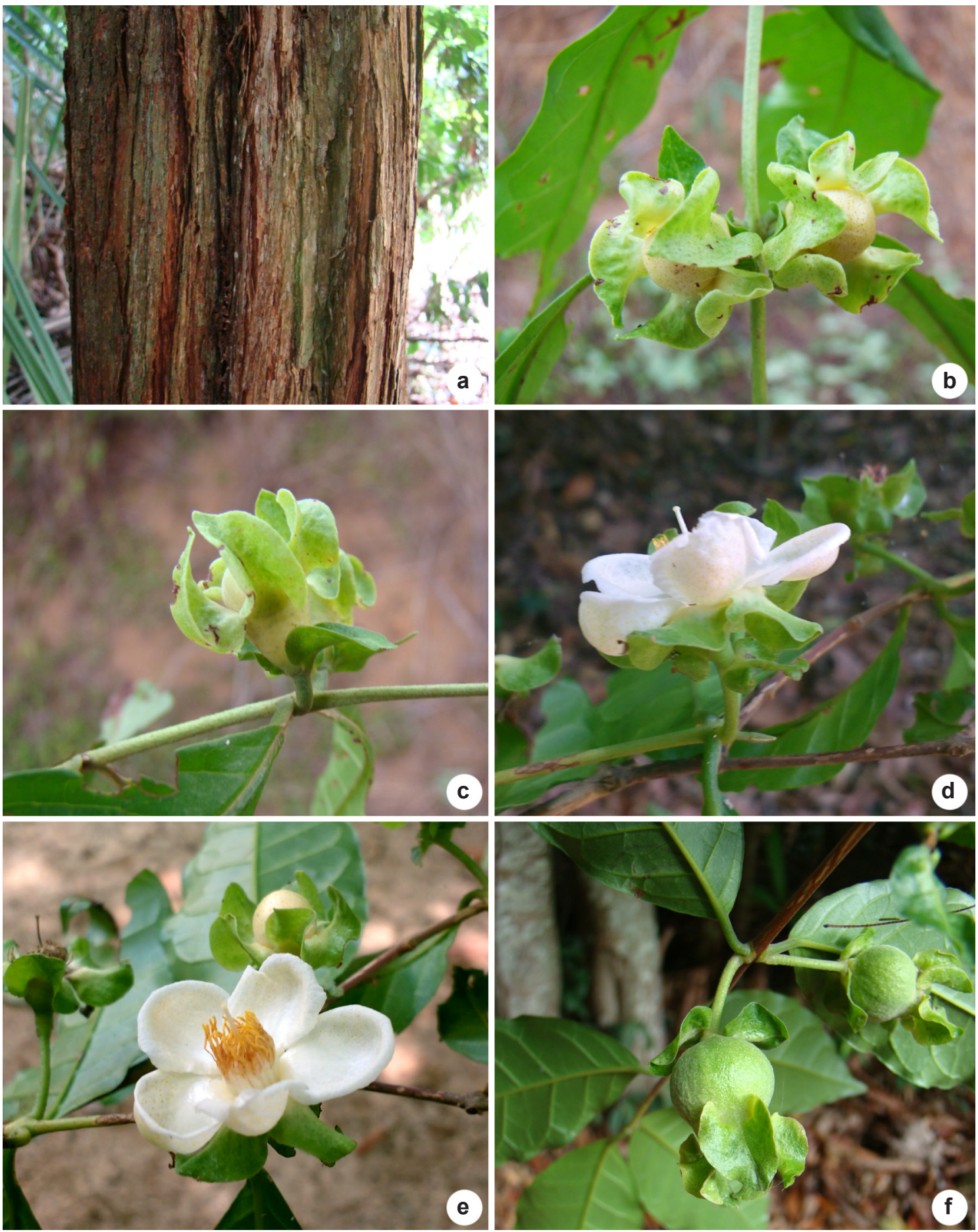

Figura 9 - a-f. Campomanesia sepalifolia - a. ritidoma; b. botão floral com destaque para as sépalas folhosas; c. botão floral com destaque para as bractéolas desenvolvidas; $d$. flor com destaque para as sépalas e bractéolas; e. flor; f. fruto jovem com bractéolas persistentes e sépalas desenvolvidas.

Figure 9-a-f. Campomanesia sepalifolia - a. rhytidoma; b. flower bud with featured for leafy sepals; $c$. flower bud with featured for developed bracteoles; d. flower with featured for developed sepals and bracteoles; e. flower; f. fruit imature with persistent bracteoles and developed sepals. 
$3 \mathrm{~h})$ e pelo tamanho $(6,46-17,6 \times 2,51-6,53 \mathrm{~cm})$, apresentando nervação adaxial bem marcada, e pela forma do fruto (Figs. 5j; 9f; 3j; 7i) (arredondando e sem ornamentação). Entretanto, C. sepalifolia difere de C. laurifolia por ter sépalas foliáceas (Figs. 5e,g,j; 9b,c,f) que apresentam a base subcordada e bractéolas desenvolvidas persistentes no fruto (Figs. 5c,j; 9c,f).

Campomanesia sepalifolia é endêmica da Floresta Atlântica, tendo registros apenas para o município de Águia Branca, noroeste do Espírito Santo (Fig. 10d). A espécie ocorre entre 100 e 300 $\mathrm{m}$ de altitude em fragmentos florestais cercados por plantios e pastagens, estando esses fragmentos sob uma forte influência antrópica. A espécie é aqui categorizada como criticamente ameaça (B1, B2a, B2b (iii) e D) segundo os critérios da IUCN (2013), principalmente pela área de ocorrência ser restrita, como uma área de ocupação conhecida de aproximadamente $10 \mathrm{~km}^{2}$. Cerca de dez indivíduos em fase reprodutiva foram observados na área. Coletada com botão floral em março, novembro, dezembro e janeiro, com flor em janeiro e com fruto em abril.

12. Campomanesia sessiliflora (O.Berg) Mattos, Loefgrenia 26:26. 1967. Figs. 6a-d; 8i-k; 10d

Árvores ou arbustos, de $5-17 \mathrm{~m}$ de alt. Folhas opostas cruzadas com pecíolo 2,7-6,3 $\times$ 0,9-1,8 mm, canaliculado ou cilíndrico, piloso, glanduloso ou não; lâminas 3,86-9,78 × 2,02-3,36 $\mathrm{cm}$, cartáceas, elípticas, ápice agudo, base cuneada, superfície lisa, plana, discolor, lustrosa ou não na face abaxial, lustrosa na face adaxial, domácias no encontro da nervura secundária com a primária ausentes; 5-8 pares de nervuras secundárias, proeminentes na face abaxial e impressas na face adaxial, pilosas. Inflorescências unifloras. Flores com pedicelo $0,5 \times 0,6 \mathrm{~cm}$ ou sésseis, piloso, não glanduloso; brácteas ca. 3,4 $\times 1 \mathrm{~mm}$, sésseis, elípticas, crassas; bractéolas 1,7-3,9 $\times$ 1-2 mm, sésseis, deltoides ou elípticas, crassas, não persistentes nos frutos; botão 8-8,8 × 6,9-7,4 $\mathrm{mm}$, cálice com abertura regular na antese, não apiculado; (5-)4-sépalas, 5,2-5,8 × 5-5,1 mm, ápice levemente recurvado pra trás, cartáceas, deltoides, face interna e externa, pilosa, não glandular; pétalas não observadas; estames ca. 130; filete ca. $2 \mathrm{~mm}$ de comp., inserção basifixa, glândula terminal ausente; antera com ápice arredondado 0,9-1 $\times$ $0,2-0,5 \mathrm{~mm}$; estilete $4,2-5,5 \mathrm{~mm}$ de compr.; disco floral côncavo a plano ca. 9,7 mm diâm., piloso, não glanduloso; ovário 14 locular, ca. 10 óvulos por lóculo; lóculos desenvolvidos não observados. Frutos não mensurados, epicarpo não rígido quando maduro, globosos, glabros ou pilosos, verdes com leves sulcos na superfície quando imaturos, lisos, sépalas persistentes inteiras no fruto. Sementes não vista.

Material examinado: Muqui, 24.IV.2007, fr., A.P. Fontana, L. Kollmann \& K.A. Brahim 3142 (MBML). Santa Teresa, 16.VII.2002, fr., R.R. Vervloet, E. Bausen \& W. Pizziolo 462 (MBML); 4.VIII.2006, fr., R.C. Britto \& L.N. Lima 104 (MBML).

Campomanesia sessiliflora ocorre na Bolívia, Paraguai e no Brasil (Trópicos 2016), sendo sua ocorrência neste país conhecida para os estados da Bahia, Minas Gerais, São Paulo, Espírito Santo, Goiás e Mato Grosso (BFG 2015). É categorizada como pouco preocupante (LC) quanto ao estado de conservação (BFG 2015). No Espírito Santo, C. sessiliflora foi encontrada na região serrana e sul do estado (Fig. 10d). Encontrada com fruto nos meses de abril e agosto.

Campomanesia sessiliflora assemelha-se com C. phaea, por ambas apresentarem filotaxia oposta cruzada e a lâmina foliar lanceolada e diminuta, além de apresentar frutos grandes e com epicarpo não rígido quando maduros. No entanto, C. sessiliflora caracteriza-se pelo ritidoma descamando em placas irregulares, flores com pedicelos menores (ca. $0,5 \times 0,6 \mathrm{~cm}$ ou séssil), a divisão das sépalas no botão não ser claramente distinguíveis, apresentando ápices levemente recurvados para trás (Figs. 6b; 8i), e frutos globosos, não discoides (Figs. 6c; 8j,k).

13. Campomanesia xanthocarpa Mart. ex $\mathrm{O}$. Berg, Fl. bras. 14(1): 451. $1857 . \quad$ Figs. 6e-g; 10d

Árvores ou arbustos de 1,5-18 m de alt. Folhas opostas dísticas com pecíolo 4,6-10,5 × 0,4-0,6 mm, canaliculado, piloso, glanduloso; lâminas 4,02-5,86 × 2,12-2,59 cm, cartáceas, elípticas ou lanceoladas, ápice atenuado, base arredondada ou cuneada, superfície bulada ou lisa, plana ou revoluta, discolor, opaca na face abaxial e na face adaxial, domácias no encontro da nervura secundária com a primária ausentes; 5 pares de nervuras secundárias, proeminentes na face abaxial e impressas na face adaxial, glabras ou pilosas. Inflorescência unifloras. Flores com pedicelo $8,6-22,7 \times 0,5-0,7 \mathrm{~mm}$, piloso, glanduloso; brácteas não observadas; bractéolas ca. $2,1 \times 0,4 \mathrm{~mm}$, sésseis, lineares, cartáceas, não persistentes nos frutos; botão ca. 4,6 $\times 5,2 \mathrm{~mm}$, cálice com abertura regular na antese, não apiculado; (5-)4-sépalas, 1,7-3 × 2-4,8 

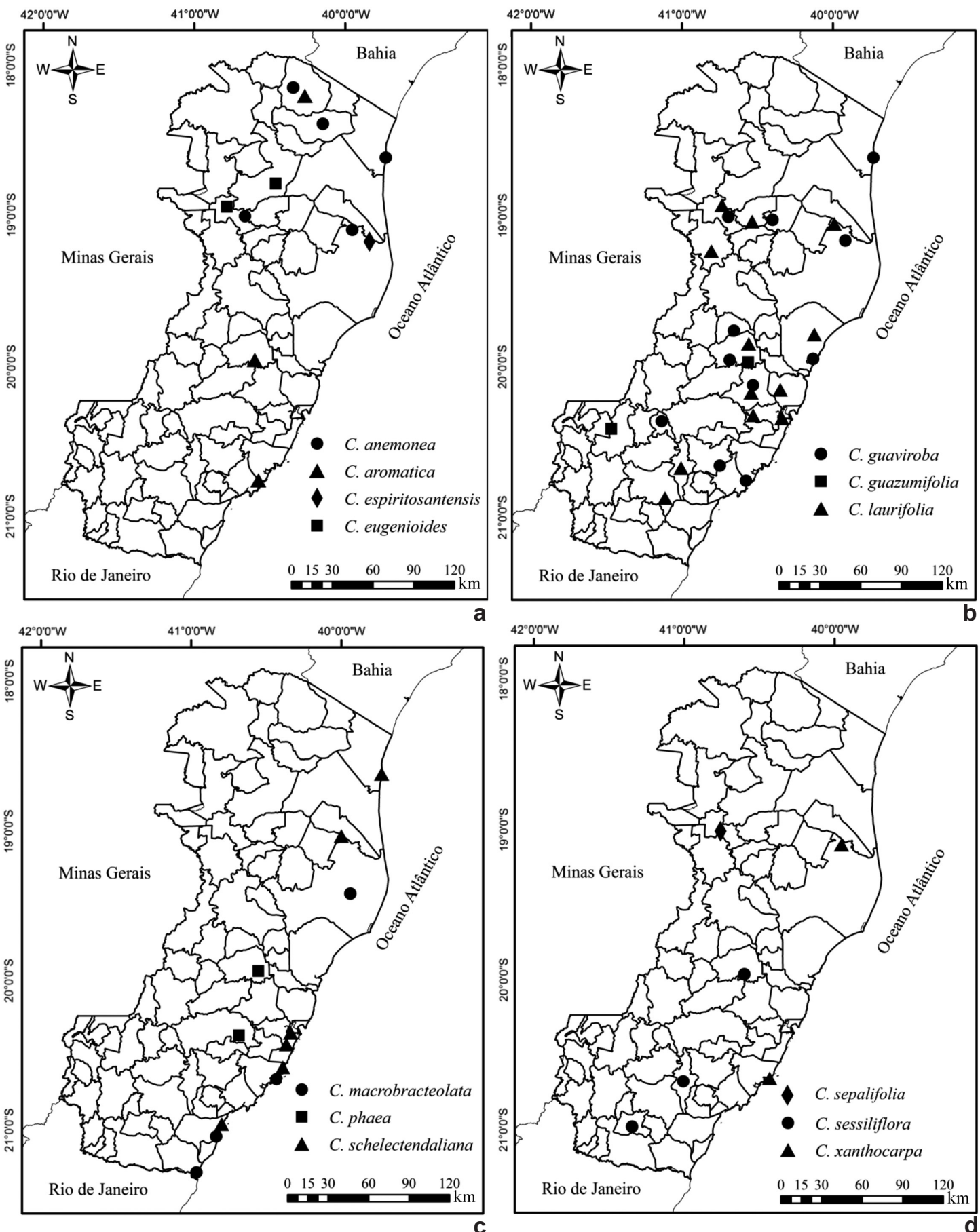

Figura 10 - Distribuição geográfica das espécies de Campomanesia no estado do Espírito Santo - a. C. anemonea, C. aromatica, C. espiritosantensis e C. eugenioides; b. C. guaviroba, C. guazumifolia e C. laurifolia; c. C. macrobracteolata, C. phaea e C. schlechtendaliana. d. C. C. sepalifolia, sessiliflora e C. xanthocarpa.

Figura 10 - Geographic distribution of Campomanesia species in Espírito Santo state-a. C. anemonea, C. aromatica, C. espiritosantensis and C. eugenioides; b. C. guaviroba, C. guazumifolia and C. laurifolia; c. C. macrobracteolata, C. phaea and C. schlechtendaliana. d. C. sepalifolia, C. sessiliflora and C. xanthocarpa. 
mm, cartáceas, deltoides ou estreito-elípticas, face interna pilosa, não glandular, face externa glabra ou pilosa, glandular; pétalas não observadas; estames não quantificados; filete não mensurado, inserção basifixa, glândula terminal presente ou não; antera com ápice arredondado ca. 0,9 × 0,6 mm; estilete não mensurado; disco floral convexo ca. 3,9 mm diâm., glabro, não glanduloso; ovário 7-11 locular, ca. 7 óvulos por lóculo, ca. 1 lóculos desenvolvidos. Frutos 9,4-13,1 × 10,4-14,4 mm, globosos, glabros, roxos quando maduros, lisos, sépalas persistentes inteiras no fruto. Sementes $6,7-7,7 \times 2,8-3,1 \mathrm{~mm}$, elípticas, ca. 1 por fruto. Material examinado: Guarapari, 14.XII.2013, fr., A.C.S. Dal Col e J. Rodrigues Filho 236 (VIES). Linhares, 27.X.1992, bot., V. de Souza 384 (CVRD). Jaguaré, 28.XII.2010, fr., D.A. Folli 6756 (CVRD).

Campomanesia xanthocarpa tem registro para Argentina, Bolívia, Paraguai, Uruguai e Brasil (Trópicos 2016). Neste país, é conhecida para os estados da Bahia, Mato Grosso do Sul, Goiás, Espírito Santo, Minas Gerais, Rio de Janeiro, São Paulo, Paraná, Santa Catarina e Rio Grane do Sul (BFG 2015), sendo categorizada como pouco preocupante (LC) em relação ao seu estado de conservação (BFG 2015). No Espírito Santo foi encontrada na região norte, em floresta de tabuleiro e em restinga, e ao sul apenas em vegetação de restinga (Fig. 10d). Encontrada com botão no mês de outubro e com frutos no mês de dezembro.

Campomanesia xanthocarpa assemelha-se a C. aromatica pelo formato lanceolado da lâmina foliar e pelo diâmetro do disco floral (3,8 a 3,9 $\mathrm{mm})$. No entanto, $C$. xanthocarpa caracteriza-se por apresentar disco floral convexo (Fig. 6e) e nervuras secundárias bem marcadas na superfície da lâmina foliar, sendo esta bulada (raramente lisa).

\section{Agradecimentos}

Os autores agradecem à UFES, o apoio logístico (laboratório e veículos para realização das excursões); aos curadores dos herbários visitados, a disponibilização dos materiais para estudo. À FAPES, a bolsa de Mestrado concedida a J. Luber e o financiamento à pesquisa concedido a M.F.S. Ferreira (processo 59152982/2012). Ao CNPq, a bolsa de Produtividade em pesquisa concedida a T.T. Carrijo e M.F.S. Ferreira. Ao IEMA, gestores e funcionários das UCs visitadas, o apoio. Aos proprietários de áreas particulares, por concederem permissão para coletas em suas propriedades, em especial ao Senhor Woito
Krok, cuja propriedade particular preservada é a localidade típica de Campomanesia sepalifolia. A Joelcio Freitas, as ilustrações.

\section{Referências}

Amorim BS \& Alves M (2012) A new record for northeastern Brazil. Check List 8: 597-599.

Aragão JG \& Conceição MG (2008) Myrtaceae: espécies das subtribos Eugeniinae, Myrciinae e Myrtinae registradas para o estado do Maranhão. Revista Sinapse Ambiental 5: 7-17.

Assis AMDE, Pereira OJ \& Thomaz LD (2004) Fitossociologia de uma floresta de restinga no Parque Estadual Paulo César Vinha, Setiba, município de Guarapari (ES). Revista Brasileira de Botânica 2: 349-361.

Bachman S, Moat J, Hill AW, de la Torre J \& Scott B (2011) Supporting red list treat assessment with GeoCAT: geospatial conservation assessment tool. ZooKeys 150: 117-126.

Berg O (1857-1859) Myrtaceae. In: Martius CFP von, Eichler AW \& Urban I (eds.) Flora brasiliensis. Lipsae, Munchen. Vol.14, pp. 430-465.

BFG - The Brazil Flora Group (2015) Growing knowledge: an overview of seed plant diversity in Brazil. Rodriguésia 66: 1085-1113.

Brummitt RK \& Powell CE (1992)Authors of plant names. Royal Botanic Gardens, Kew. TDWG Standard. Disponível em <http://www.kew.org/data/authors. html $>$. Acesso em 2016.

Carrara MR (1997) Estudo das espécies de Campomanesia Ruiz \& Pav. (Myrtaceae, Myrtinae) ocorrentes no estado do Rio de Janeiro. Dissertação de Mestrado. Universidade Federal do Rio de Janeiro/Museu Nacional, Rio de Janeiro. 223p.

Dutra VF, Alves-Araújo A \& Carrijo TT (2015) Angiosperm checklist of Espírito Santo: using electronic tools to improve the knowledge of an Atlantic Forest biodiversity hotspot. Rodriguésia 66: 1145-1152.

Giaretta A, De Menezes LFT \& Peixoto AL (2015) Diversity of Myrtaceae in the southeastern Atlantic forest of Brazil as a tool for conservation. Brazilian Journal of Botany 38: 175-185.

Global Plants on Jstor (2016) Disponível em <https:// plants.jstor.org/>. Acesso em 2015.

GOOGLE - Google Earth website (2009) Disponível em $<$ http://earth.google.com/>. Acesso em 2016.

Hickey M \& King C (2000) The Cambridge illustrated glossary of botanical terms. Cambridge University Press, Cambridge. Pp. 1-222.

Hijmans RJL, Guarino C, Bussink P, Mathur M, Cruz IB \& Rojas E (2004) DIVA-GIS. Versão 5.0. A geographic information system for the analysis of species distribution data. Disponível em <http:// www.diva-gis.org>. 2016. 
Kawasaki ML (2000) A new species of Campomanesia (Myrtaceae) from southeastern Brazil. Brittonia 52: 188-190.

Kawasaki ML (2004) Flora de Grão-Mogol, Minas Gerais: Myrtaceae. Boletim de Botânica da Universidade de São Paulo 22: 323-337.

Landim MR \& Landrum LR (2002) The genus Campomanesia (Myrtaceae) in Atlantic rainforest fragments in Sergipe, northeast region of Brazil. Sida 20: 205-214.

Landrum LR \& Oliveira MIU (2010) A new species of Campomanesia (Myrtaceae) from Bahia, Brazil, based on specimens collected by js blanchet over 150 years ago. Journal of the Botanical Research Institute of Texas 4: 603-607.

Landrum LR (1986) Campomanesia, Pimenta, Blepharocalyx, Legrandia, Acca, Myrrhynium and Luma (Myrtaceae). Flora Neotropica. Monograph 45. The New York Botanical Garden, New York. Pp. 1-178.

Landrum LR (2002) Two new species of Campomanesia (Myrtaceae) from Espírito Santo and Bahia, Brazil. Brittonia 53: 534-538.

Lawrence GHM, Buchheim AFG, Daniels GS \& Dolezal H (1968) Botanicum-Periodicum-Huntianum. Hunt Botanical Library, Pittisburgh. 1063p.

Lima DF, Goldenberg R \& Sobral M (2011) O gênero Campomanesia (Myrtaceae) no estado do Paraná, Brasil. Rodriguésia 62: 683-693.

McVaugh R (1968) The genera of American Myrtaceae an interim report. Taxon 17: 354-418.

Morais PO \& Lombardi JA (2006) A Família Myrtaceae na Reserva Particular do Patrimônio Natural da Serra do Caraça, Catas Altas, Minas Gerais, Brasil. Lundiana 7: 3-32.

Oliveira MIU, Funch LS \& Landrum LR (2012) Flora da Bahia: Campomanesia (Myrtaceae). Sitientibus série Ciências Biológicas 12: 91-107.

Oliveira MIU, Landrum LR, Oliveira RP \& Funch LS (2013) Anew species of Campomanesia (Myrtaceae) from Bahia, Brazil, and its relationships with the C. xanthocarpa complex. Phytotaxa 149: 19-26.
Pereira OJ \& Assis AM (2000) Florística da restinga de Camburi, Vitória, ES. Acta Botanica Brasílica 14: 99-111.

Proença CEB, Soares-Silva LH, Silva PIT \& Fank-deCarvalho SM (2010) Two new endemic species of Myrtaceae and an anatomical novelty from the Highlands of Brazil. Kew Bulletin 65: 463-468.

Proença CEB, Jennings LVS \& Lucas EJ (2011) Two new species of Myrtaceae (Myrteae) from northern South America. Brittonia 63: 46-50.

Reflora (2017) Herbário virtual. Disponível em $<$ http:// reflora.jbrj.gov.br/jabot/PrincipalUC/PrincipalUC. do>. Acesso em 14 abril 2017.

Ruiz H \& Pavón JA (1794) Florae Peruvianae, et Chilensis Prodromus, sive novorum generum plantrum peruvianum, et chilensium descriptiones et icones. Sanchea, Madrid. Pp. 62-63.

Santos MF \& Sano PT (2012) Flora of the Serra do Ouro Branco, Minas Gerais: Myrtaceae. Rodriguésia 63: 1065-1083.

Sobral M (2003) A família Myrtaceae no Rio Grande do Sul. Unisinos, São Leopoldo. 215p.

Species Link (2017) Species Link. Disponível em $<$ http://splink.cria.org.br/>. Acesso em 14 abril 2017.

Stadnik A, Ibrahim M \& Roque N (2016) Levantamento florístico de Myrtaceae no município de Jacobina, Chapada Diamantina, estado da Bahia, Brasil. Hoehnea 43: 87-97.

Stafleu FA \& Cowan RS (1979) Taxonomic literature. A selective guide to botanical publications and collections with dates, commentaries and types. Volume II: H-Le. $2^{\text {nd }}$ ed. Bohn, Scheltema \& Holkema, Utrecht; Dr. W. Junk B.V. Publishers, The Hague. 1136p.

Thiers B [continuamente atualizado] Index Herbariorum: a global directory of public herbaria and associated staff. New York Botanical Garden's Virtual Herbarium. Disponível em $<$ http://sweetgum.nybg. org/ih/>. Acesso em 16 outubro 2015.

Tropicos (2016) Disponível em <http://www.tropicos. org/>. Acesso em 2015/2016. 